\title{
Three new species of subterranean amphipods (Pseudocrangonyctidae: Pseudocrangonyx) from limestone caves in South Korea
}

\author{
Chi-Woo Lee ${ }^{1}$, Gi-Sik Min ${ }^{\text {Corresp. } 1}$ \\ ${ }^{1}$ Biological Sciences, Inha University, Incheon, South Korea \\ Corresponding Author: Gi-Sik Min \\ Email address: mingisik@inha.ac.kr
}

Pseudocrangonyx Akatsuka \& Komai, 1922 is the most diverse group of subterranean amphipods in the groundwater communities of Far East Asia. In Korea, the diversity of the group has been underestimated due to the records of morphological variants of Pseudocrangonyx asiaticus Uéno, 1934. To estimate the species diversity, we analyzed the morphological characteristics and conducted molecular analyses of specimens collected from Korean caves that we treated as morphological variants of $P$. asiaticus. We described three new subterranean pseudocrangonyctid amphipod species, $P$. deureunensis sp. nov., $P$. kwangcheonseonensis sp. nov., and $P$. hwanseonensis sp. nov., from the groundwater of limestone caves in South Korea. Additionally, we determined sequences of the nuclear large subunit ribosomal RNA and the mitochondrial cytochrome $c$ oxidase subunit I gene of the new species for molecular analyses. Molecular phylogenetic analyses revealed that the three new species formed a monophylum together with $P$. joolaei Lee et al., 2020 and $P$. wonkimi Lee et al., 2020, which are species that are endemic to Korean caves. 


\section{Three new species of subterranean amphipods}

2 (Pseudocrangonyctidae: Pseudocrangonyx) from

3 limestone caves in South Korea

4

Chi-Woo Lee ${ }^{1}$, Gi-Sik Min ${ }^{1}$

6

7

${ }^{1}$ Department of Biological Sciences, Inha University, Incheon, South Korea

8

Corresponding Author:

Gi-Sik Min ${ }^{1}$

Incheon, South Korea

Email address: mingisik@inha.ac.kr

\section{Abstract}

Pseudocrangonyx Akatsuka \& Komai, 1922 is the most diverse group of subterranean amphipods in the groundwater communities of Far East Asia. In Korea, the diversity of the group has been underestimated due to the records of morphological variants of Pseudocrangonyx asiaticus Uéno, 1934. To estimate the species diversity, we analyzed the morphological characteristics and conducted molecular analyses of specimens collected from Korean caves that we treated as morphological variants of $P$. asiaticus. We described three new subterranean pseudocrangonyctid amphipod species, $P$. deureunensis sp. nov., $P$. kwangcheonseonensis $\mathbf{s p .}$ nov., and $P$. hwanseonensis sp. nov., from the groundwater of limestone caves in South Korea. Additionally, we determined sequences of the nuclear large subunit ribosomal RNA and the mitochondrial cytochrome $c$ oxidase subunit I gene of the new species for molecular analyses. Molecular phylogenetic analyses revealed that the three new species formed a monophylum together with . joolaei Lee et al., 2020 and $P$. wonkimi Lee et al., 2020, which are species that are endemic to Korean caves.

\section{Introduction}

Amphipods are the most diverse group of organisms in groundwater communities (Holsinger 1994), and subterranean amphipods are even more notable from a biogeographic perspective because of their limited dispersal ability and restriction to groundwater aquifers (Holsinger 1993). Most subterranean amphipods are troglobiont (stygobiont) and are generally characterized by morphological features such as appendage elongation and the loss of eyes and pigment (Holsinger 1994; Väinölä et al. 2007). These characteristics result in the strikingly convergent morphology of these cave animals (Jones et al. 1992). Classifying subterranean organisms solely on their morphological characteristics leads to several taxonomic problems (Lefébure et al. 2006; 
to morphologically identify, molecular analyses help in species delimitation (Lefébure et al. 2006; Trontelj et al. 2009; Hou \& Li 2010).

The stygobitic amphipod genus Pseudocrangonyx Akatsuka \& Komai, 1922 is the most diverse taxon among the subterranean amphipod genera found in Far East Asia, i.e., the Korean Peninsula, the Japanese Archipelago, eastern China, and the Russian Far East (Sidorov \& Holsinger 2007; Tomikawa \& Nakano 2018). The first record of $P$. asiaticus Uéno, 1934 on the Korean Peninsula was from North Korea (Uéno 1940). However, P. asiaticus's type locality is on China's Liaodong Peninsula (Uéno 1934). Using identification techniques based on morphological characteristics, this species has been found to inhabit several caves in South Korea (Uéno 1966; Holsinger 1989). Uéno (1966) mentioned regional morphological variants of the Korean populations, but did not regard them as a distinct species. At that time, there were obvious limitations to correctly identifying subterranean amphipods based solely on morphological characteristics. Recent studies have used molecular analyses and morphological identification to show that the genus' species diversity may be higher than previously believed (Tomikawa et al. 2016; Tomikawa \& Nakano 2018; Lee et al. 2020).

While conducting cave surveys on the Korean Peninsula, we collected Pseudocrangonyx specimens from two caves (Kwangcheonseon Cave and Hwanseon Cave) where Uéno (1966) reported finding one of the $P$. asiaticus Uéno, 1934 morphological variants. Additionally, specimens were also collected from Deureune Cave, where the genus Pseudocrangonyx had not been previously located. Based on the results of morphological examination of the amphipods, we described and illustrated them as three new Pseudocrangonyx species. Furthermore, we determined the nuclear large subunit ribosomal RNA (28S rRNA) gene and mitochondrial cytochrome $c$ oxidase subunit I (COI) gene sequence data for molecular analyses of the three new species. Additionally, we provided a key to the Korean Pseudocrangonyx species.

\section{Materials \& Methods}

Sample collection and morphological examination. Pseudocrangonyx specimens were collected from the groundwater of three Korean caves: Deureune Cave (Fig. 1A), Kwangcheonseon Cave (Fig. 1B), and Hwanseon Cave (Fig. 1C). We fixed and preserved the specimens in $99 \%$ ethanol. All specimen appendages were dissected in $80 \%$ ethanol and mounted with gum-chloral medium on glass slides under an Olympus SZX7 stereomicroscope (Tokyo, Japan). The specimens were examined using a Nikon Eclipse Ni light microscope (Tokyo, Japan) and were illustrated with the aid of a drawing tube. The body length from the tip of the rostrum to the base of the telson was measured along the dorsal curvature to the nearest $0.1 \mathrm{~mm}$. The nomenclature of the setal patterns on the mandibular palp followed the method described by Stock (1974). The specimens examined in this study have been deposited in the collection at the Nakdonggang National Institute of Biological Resources, Korea (NNIBR). Molecular analyses. We extracted genomic DNA from the muscles of the specimen appendages using the LaboPass Tissue Mini Kit (Cosmo GENETECH, Seoul, South Korea), according to the manufacturer's instructions. We used the following primer sets for the PCR reaction used in this 
study: 28F and 28R for 28S rDNA (Hou et al. 2007), and LCO1490 and HCO2198 for COI (Folmer et al. 1994). The sequences of 28S rDNA were aligned using MAFFT v. 7.388 L-INS-i (Katoh \& Standley 2013), and COI was aligned using Geneious 8.1.9 (Biomatters, Auckland, New Zealand). For phylogenetic analysis, these two alignments were combined. All data used in molecular analyses were provided, including the newly obtained sequences (Table 1). Pairwise comparisons of uncorrected $p$-distances for COI sequences were calculated using MEGA X (Kumar et al. 2018). Phylogenetic trees were constructed using maximum likelihood (ML) and Bayesian inference (BI). We performed ML analysis using RAxML v. 8.2.10 (Stamatakis 2014) with the substitution model immediately set as GTRCAT after nonparametric bootstrapping was conducted with 1,000 replicates. The best fit-partitioning scheme for the ML analysis was identified with the Akaike information criterion using PartitionFinder v. 2.1.1 (Lanfear et al. 2017 ) with the "greedy" algorithm. BI and posterior probabilities were estimated using MrBayes v. 3.2.6 (Ronquist et al. 2012). Two independent runs of four Markov chains were conducted for 10 million generations, and the tree was sampled at every 100 generations. Parameter estimates and convergence were checked using Tracer v. 1.7.1 (Rambaut et al. 2018), and the first 50001 trees were discarded based on results.

Scanning electron microscopy. To carry out scanning electron microscope (SEM) imaging, we rinsed the specimen with TWEEN 20 (Model 036K00963; Sigma, St. Louis, MO, USA) to remove residual debris, and then dehydrated the sample with a graded ethanol series $(30 \%, 50 \%$, $70 \%, 80 \%, 95 \%$, and $100 \%$ ethanol; 10 min each) and hexamethyldisilazane (Sigma, St. Louis, MO, USA) for $1 \mathrm{~h}$. The dried sample was sputtered with platinum, and then observed using an SEM (Model Hitachi S-4300; Japan).

Terminology. Pseudocrangonyx asiaticus sensu stricto refers to the species that was originally described by Uéno (1934).

The electronic version of this article in Portable Document Format (PDF) will represent a published work according to the International Commission on Zoological Nomenclature (ICZN), and hence the new names contained in the electronic version are effectively published under that Code from the electronic edition alone. This published work and the nomenclatural acts it contains have been registered in ZooBank, the online registration system for the ICZN. The ZooBank LSIDs (Life Science Identifiers) can be resolved and the associated information viewed through any standard web browser by appending the LSID to the prefix http://zoobank.org/. The LSID for this publication is: [urn:lsid:zoobank.org:pub:A60F095A-2A50-4D87-876C6D8E3D8539CE]. The online version of this work is archived and available from the following digital repositories: PeerJ, PubMed Central and CLOCKSS.

\section{Results}

Order Amphipoda Latreille, 1816

Family Pseudocrangonyctidae Holsinger, 1989

Genus Pseudocrangonyx Akatsuka \& Komai, 1922 
119

120

121

122

123

124

125

126

127

128

129

130

131

132

133

134

135

136

137

138

139

140

141

142

143

144

145

146

147

148

149

150

151

152

153

154

155

156

157

158

\section{Pseudocrangonyx deureunensis sp. nov.}

urn:lsid:

[New Korean name: deu-reu-ne-dong-gul-yeop-sae-u]

(Figs 2A, 3-8)

Material examined. Holotype female $(9.8 \mathrm{~mm})$, NNIBRIV39838, collected from Deureune Cave $\left(37^{\circ} 4.75^{\prime} \mathrm{N}, 128^{\circ} 59.36^{\prime} \mathrm{E}\right)$, Bonghwa-gun, Gyeongsangbuk-do, Korea, on 25 May 2018, by C. -W. Lee. Paratypes: 1 female (8.2 mm), NNIBRIV39835 (fig. 2A); 1 male (7.1 mm), NNIBRIV39839, collection data same as that for the holotype.

Diagnosis. Antennal sinus with rounded angle; eyes absent; pereonites 1-6 with short dorsal setae; dorsal margin of urosomites 1-3 with setae; pereonites 2-4 each with sternal gill; antenna 1 being 0.51 times as long as body length; antenna 2 with calceoli in both sexes; mandible palp article 3 longer than article 2; maxilla 1 outer plate with 7 serrate teeth; maxilla 2 inner plate with oblique inner row of 6 setae; gnathopods 1 and 2, carpi with serrate setae on posterodistal corners in both sexes; palmar margins of propodi of gnathopods 1 and 2 with 11-15 and 14-18 robust setae, respectively; pleopod peduncles lacking marginal setae, inner margin of inner rami with bifid setae; uropod 1 inner ramus 0.9 times as long as peduncle, inner and outer margins of inner ramus with 3 and 2 robust setae, respectively, basal part of inner ramus with 3 slender setae, outer ramus with 2 marginal robust setae; uropod 2 inner ramus 1.2 times as long as peduncle, outer ramus with 2 marginal robust setae; uropod 3 terminal article longer than adjacent robust setae; telson each lobe with 2 apical robust setae and 1 penicillate seta.

Description. Female holotype (NNIBRIV39838). Head (Fig. 3A) with short dorsal seta; rostrum short; lateral cephalic lobe rounded; antennal sinus with rounded angle; eyes absent. Pereonites 1-6 with short dorsal setae; dorsal margin of pereonite 7 with long setae. Dorsal margins of pleonites 1-3 with long setae (Fig. 3B). Posterior margin of epimeral plate 1 with 6 setae, posteroventral corner with seta; ventral and posterior margins of plate 2 with 3 and 4 setae, respectively, posteroventral corner with seta; ventral and posterior margins of plate 3 with 3 setae, respectively, posteroventral corner subquadrate with seta (Fig. 3B). Dorsal margin of urosomites 1-3 with setae. Anteroventral corner of urosomite 1 with seta, posteroventral corner of urosomite 3 with setae (Fig. 3B).

Antenna 1 (Fig. 3C) 0.51 times as long as body length, peduncular articles 1-3 in length ratio of $1.0: 0.7: 0.4$; accessory flagellum (Fig. 3D) 2-articulate, more than shorter primary flagellar article 1, terminal article with 3 setae and 1 aesthetasc; primary flagellum 18-articulate, 1 aesthetasc on some articles. Antenna 2 (Fig. 3E, F) 0.59 times as long as antenna 1; peduncular article 5 with 2 calceoli; flagellum 0.65 times as long as peduncular articles 4 and 5 combined, consisting of 9 articles, first 5 each with calceolus.

Upper lip (Fig. 3G) with rounded anterior margin, with fine setae. Mandibles (Fig. 3H-J) with left and right incisors with 5-dentate, respectively; left lacinia mobilis 5-dentate, right lacinia bifid, with many teeth; molar process triturative; accessory setal rows of left and right 
159

160

161

162

163

164

165

166

167

168

169

170

171

172

173

174

175

176

177

178

179

180

181

182

183

184

185

186

187

188

189

190

191

192

193

194

195

196

197

198

mandibles each with 6-pectinate setae, respectively; palp 3-articulate, article 3 with 5 A-, 15 D-, and 2 E-setae. Lower lip (Fig. 3K) with broad outer lobes with fine setae, mandibular process of outer lobe rounded apically; inner lobes indistinct. Maxilla 1 (Fig. 3L) with inner and outer plates, and palp; inner plate subovate with 5 plumose setae; outer plate subrectangular with 7 serrate teeth apically; palp 2-articulate, longer than outer plate, article 2 with weakly plumose robust seta apically, and 3 apical and 4 subapical robust setae. Maxilla 2 (Fig. 4A) with oblique inner row of 6 setae on inner plate. Maxilliped (Fig. 4B, C) with inner and outer plates, and palp; inner plate subrectangular with 4 apical robust setae; outer plate suboval with apical and subapical 4 robust setae, and some medial setae; palp 4-articulate, medial margin of article 2 lined with setae, article 4 with nail.

Gnathopod 1 (Fig. 4D, E) with subquadrate coxa, bearing seta on anterior dorsal margin and anterodistal corner, width 1.8 times as long as depth; basis thick and short, anterior margin bare, submargin with setae, posterior margin with 16 long setae; posterodistal corner of carpus with 2 serrate robust setae; propodus stout, subtriangular, palmar margin with 15 robust setae in 2 rows, some distally notched; posterior margin of dactylus dentate (Fig. 4F). Gnathopod 2 (Fig. 4G, H) with rounded coxa, with setae on its anterior to ventral margins, width 1.4 times as long as depth; basis slender with anterior margin bare, posterior margin with 8 long setae; posterodistal corner of carpus with 3 serrate robust setae; propodus more slender than that of gnathopod 1, palmar margin with 18 robust setae in 2 rows, some distally notched; posterior margin of dactylus dentate (Fig. 4I). Pereopod 3 (Fig. 5A) with subquadrate coxa bearing setae on anterodistal corner to ventral margins, width 1.5 times as long as depth; anterior and posterior margins of basis with setae; merus, carpus, and propodus in length ratio of $1.0: 0.9: 0.9$; posterior margin of dactylus with 2 setae (Fig. 5B). Pereopod 4 (Fig. 5C) with subquadrate coxa bearing setae on anterior margin, anterodistal corner and ventral margin, width 1.6 times as long as depth; anterior and posterior margins of basis with setae; merus, carpus, and propodus in length ratio of $1.0: 0.9$ : 1.0; posterior margin of dactylus with 2 setae (Fig. 5D). Pereopod 5 (Fig. 5E) with bilobed coxa bearing setae on anterior and posterior lobes; anterior and posterior margins of basis with setae; merus, carpus, and propodus in length ratio of $1.0: 1.0: 1.1$; anterior margin of dactylus with 2 setae (Fig. 5F). Pereopod 6 (Fig. 5G) anterior coxa broken; bearing setae on posterior lobe; anterior and posterior margins of basis with setae; merus, carpus, and propodus in length ratio of $1.0: 1.0: 1.1$; anterior margin of dactylus with 2 setae (Fig. 5H). Pereopod 7 (Fig. 5I) with subtriangular coxa, ventral margin weakly concave, with seta on ventral margin and posterodistal corner; anterior and posterior margins of basis with setae; merus, carpus, and propodus in length ratio of $1.0: 1.2: 1.2$; anterior margin of dactylus with 2 setae (Fig. 5J).

Sternal gills (Fig. 6A) on ventral surfaces of pereonites $2-4$, respectively.

Coxal gills (Figs. 4G, 5A, C, E, G) on gnathopod 2 and pereopods 3-6.

Brood plates (Figs. 4G, 5A, C, E) slender with numerous setae, on gnathopod 2 and pereopods 3-5.

Peduncles of pleopods 1-3 (Fig. 6B, D, F) lacking marginal setae, outerdistal corners with 2 setae, respectively. Pleopods 1-3 with paired retinacula (Fig. 6C, E, G), inner ramus inner basal 
199

200

201

202

203

204

205

206

207

208

209

210

211

212

213

214

215

216

217

218

219

220

221

222

223

224

225

226

227

228

229

230

231

232

233

234

235

236

237

margin with 2, 2, and 1 bifid seta (clothes-pin seta), respectively; inner ramus of pleopods 1-3 10-, 9-, and 9-articulate, respectively; outer ramus of pleopods 1-311-, 10-, and 9-articulate, respectively.

Uropod 1 (Fig. $6 \mathrm{H}$ ) with basofacial seta on peduncle; inner ramus 0.9 times as long as peduncle, inner and outer margins with 3 and 2 robust setae, respectively, basal part with 3 slender setae; outer ramus 0.7 times as long as inner, with 2 outer margin robust setae, inner margin bare. Uropod 2 (Fig. 6I) with inner ramus 1.2 times as long as peduncle, outer margin and marginal with 2 robust setae, respectively; outer ramus 0.7 times as long as inner ramus, inner margin bare and outer margin with 2 robust setae. Uropod 3 (Fig. 6J) with peduncle 0.24 times as long as outer ramus; inner ramus absent; outer ramus 2-articulate, proximal article with robust setae, terminal article 0.2 times as long as proximal article, with 3 distal setae.

Telson (Fig. 6K) laterally straight, length 1.26 times as long as wide, cleft for $36.5 \%$ of length, each telson lobe with 2 lateral penicillate setae, apical with 2 robust setae and penicillate seta.

Male paratype (NNIBRIV39839). Antenna 1 (Fig. 7A, B) 0.64 times as long as body length, primary flagellum 18-articulate, 1 aesthetasc on some articles. Antenna 2 (Fig. 7C, D) 0.6 times as long as antenna 1; flagellum 0.61 times as long as peduncular articles 4 and 5 combined, consisting of 8 articles, articles 1-2 with calceolus.

Gnathopod 1 (Fig. 7E) carpus with serrate seta on posterodistal corner; palmar margin of propodus with 11 robust setae in 2 rows, some distally notched (Fig. 7F). Gnathopod 2 (Fig. 7G) carpus with 2 serrate setae on posterodistal corner; palmar margin of propodus with 14 robust setae in 2 rows, some distally notched (Fig. $7 \mathrm{H}$ ).

Uropod 1 (Fig. 8A) with 2 basofacial setae on peduncle; inner ramus 0.76 times as long as peduncle; outer margin and marginal with 3 and 2 robust setae, respectively, basal part with 2 slender setae; outer ramus with 2 outer margin robust setae. Uropod 2 (Fig. 8B, C) with peduncle 0.82 times as long as inner ramus; inner ramus 1.4 times as long as outer ramus, distal part with 2 serrate, 4 simple robust setae. Uropod 3 (Fig. 8D, E) with outer ramus terminal article 0.2 times as long as proximal article.

Telson (Fig. 8F) length 1.2 times as long as wide, cleft for $39.1 \%$ of length.

Distribution. Known only from the type locality.

Etymology. The specific name is an adjective derived from the name of the cave where the new species was found.

Remarks. Pseudocrangonyx deureunensis sp. nov. is morphologically most similar to P.joolaei Lee et al., 2020 in having 1) eyes completely absent, 2) pereonites 1-6 with short dorsal setae, 3) ventral surface of pereonites 2-4 has sternal gills, 4) antenna 2 with calceoli in both sexes, 5) maxilla 1 outer plate with 7 serrate teeth, and 6) inner rami of pleopods with bifid setae on inner margin. The new species can be clearly distinguished from $P$. joolaei by the following characters (features of $P$. joolaei in parentheses): 1) urosomite 3 with (without) dorsal setae, 2) antenna 1 longer (shorter) than half the body length, 3) carpi of male gnathopods 1 and 2 with 1-2 (with 3 )

Peer) reviewing PDF | (2020:10:54037:1:0:NEW 22 Dec 2020) 
238

239

240

241

242

243

244

245

246

247

248

249

250

251

252

253

254

255

256

257

258

259

260

261

262

263

264

265

266

267

268

269

270

271

272

273

274

275

276

277

serrate robust setae on posterodistal corner, 4) uropod 3 terminal article longer (shorter) than adjacent robust setae, and 5) telson with 2 (with 4) apical robust setae.

\section{Pseudocrangonyx kwangcheonseonensis sp. nov.}

urn:lsid:

[New Korean name: kwang-cheon-seon-dong-gul-yeop-sae-u]

(Figs 2B, 9-14)

Pseudocrangonyx asiaticus. —Uéno, 1966: 506-518 (in part), figs. 2-4, 5A-K.

Material examined. Holotype female (10.6 mm), NNIBRIV35120, collected from

Kwangcheonseon Cave ( $\left.37^{\circ} 31.11^{\prime} \mathrm{N}, 128^{\circ} 27.05^{\prime} \mathrm{E}\right)$, Pyeongchang-gun, Gangwon-do, Korea, on 28 February 2017, by Y. G. Choi. Paratypes: 1 male (7.8 mm), NNIBRIV39840; 1 male (7.1 $\mathrm{mm})$, NNIBRIV39841, collection data same as that for the holotype.

Diagnosis. Female larger than male; antennal sinus with rounded angle; eyes absent; pereonites 1-7 with dorsal setae; dorsal margin of urosomite 3 lacking setae; pereonites 2-4 each with sternal gill; antenna 1 longer than half body length; antenna 2 with calceoli in both sexes; mandible palp article 3 longer than article 2; maxilla 1 inner plate with 8 plumose setae; gnathopods 1 and 2, carpi with serrate setae on posterodistal corners in both sexes; palmar margins of propodi of gnathopods 1 and 2 with 24-26 and 20-21 robust setae, respectively; pleopod peduncles lacking marginal setae, inner margin of inner rami with bifid setae; uropod 1, inner and outer margins of inner ramus with 4 and 3 robust setae, basal part of inner ramus with 3 slender setae, outer ramus with 3 outer marginal robust setae; uropod 3 terminal article shorter than adjacent robust setae; telson laterally concave and shallowly at the top.

Description. Female holotype (NNIBRIV35120). Head (Fig. 2B) with short dorsal setae; rostrum short; lateral cephalic lobe rounded; antennal sinus shallow with rounded angle; eyes absent. Pereonites 1-6 with short dorsal setae; dorsal margin of pereonite 7 with long setae. Dorsal margins of pleonites 1-3 with long setae (Fig. 2B). Posterior margin of epimeral plate 1 with 5 setae; ventral and posterior margins of plate 2 with 2 and 4 setae, respectively, posteroventral corner with seta; ventral and posterior margins of plate 3 with 3 setae, respectively, posteroventral corner with seta (Fig. 2B). Dorsal margin of urosomites 1-2 with setae, urosomite 3 lacking dorsal setae. Anteroventral corner of urosomite 1 with seta, posteroventral corner of urosomite 3 with setae (Fig. 2B).

Antenna 1 (Fig. 9A) 0.56 times as long as body length, peduncular articles 1-3 in length ratio of $1.0: 0.7: 0.4$; accessory flagellum (Fig. 9B) 2-articulate, more than longer primary flagellar article 1, terminal article with 3 setae and 1 aesthetasc; primary flagellum 21 -articulate, 1 aesthetasc on some articles. Antenna 2 (Fig. 9C, D) 0.64 times as long as antenna 1; peduncular article 5 with 4 calceoli; flagellum 0.52 times as long as peduncular articles 4 and 5 combined, consisting of 8 articles, first 6 each with calceolus.

Upper lip (Fig. 9E) with rounded anterior margin, with fine setae. Mandibles (Fig. 9F-H) with left and right incisors with 6- and 5-dentate, respectively; left lacinia mobilis 5-dentate, 
278 right lacinia bifid, with many teeth; molar process triturative; accessory setal rows of left and 279 right mandibles with 7 and 6 pectinate setae; palp 3-articulate, article 3 with 8 A-, 20 D-, and 5 280 E-setae. Lower lip (Fig. 9I) with broad outer lobes with fine setae, mandibular process of outer 281 lobe rounded apically; inner lobes indistinct. Maxilla 1 (Fig. 9J, K) with inner and outer plates, 282 and palp; inner plate subovate with 8 plumose setae; outer plate subrectangular with 7 serrate 283 teeth apically; palp 2-articulate, longer than outer plate, article 2 with plumose robust seta 284 apically. Maxilla 2 (Fig. 9L) with oblique inner row of 10 setae on inner plate. Maxilliped (Fig. 285 10A) with inner and outer plates, and palp; inner plate subrectangular with 4 apical robust setae; 286 outer plate suboval with apical and subapical 6 robust setae, and some medial setae; palp 4-

287

288

289

290

291

292

293

294

295

296

297

298

299

300

301

302

303

304

305

306

307

308

309

310

311

312

313

314

315

316

317 articulate, medial margin of article 2 lined with setae, article 4 with nail.

Gnathopod 1 (Fig. 10B, C) with subquadrate coxa, bearing seta on its anterior to ventral margins, width 1.7 times as long as depth; basis thick and short, anterior margin bare, posterior margin with 15 long setae; posterodistal corner of carpus with 2 serrate robust setae; propodus stout, subtriangular, palmar margin with 24 robust setae in 2 rows, some distally notched; posterior margin of dactylus dentate (Fig. 10D). Gnathopod 2 (Fig. 10E, F) with rounded coxa, with setae on its anterior to ventral margins, width 1.3 times as long as depth; basis slender with anterior margin bare, posterior margin with 16 long setae; posterodistal corner of carpus with 3 serrate robust setae; propodus more slender than that of gnathopod 1, palmar margin with 21 robust setae in 2 rows, some distally notched; posterior margin of dactylus dentate (Fig. 10G). Pereopod 3 (Fig. 11A) with subquadrate coxa bearing setae on anterior margin to posteroventral corner, width 1.4 times as long as depth; basis posterior margin with 17 long setae; merus, carpus, and propodus in length ratio of $1.0: 0.7: 0.7$; posterior margin of dactylus with 2 setae (Fig. 11B). Pereopod 4 (Fig. 11C) with subquadrate coxa bearing setae on anterior margin to posteroventral corner, width 1.6 times as long as depth; basis posterior margin with 12 long setae; merus, carpus, and propodus in length ratio of $1.0: 0.8: 0.7$; posterior margin of dactylus with seta (Fig. 11D). Pereopod 5 (Fig. 11E) with bilobed coxa bearing setae on anterior and posterior lobes; anterior and posterior margins of basis with setae; merus, carpus, and propodus in length ratio of $1.0: 1.0: 0.9$; anterior margin of dactylus with 1 seta (Fig. 11F). Pereopod 6 (Fig. 11G) with weakly bilobed coxa bearing setae on anterior and posterior lobes; anterior and posterior margins of basis with setae; merus, carpus, and propodus in length ratio of $1.0: 1.0$ : 0.9. Pereopod 7 (Fig. 11H) anterior coxa broken, ventral margin weakly concave, with setae on ventral margin and posterodistal corner; anterior and posterior margins of basis with setae; merus, carpus, and propodus in length ratio of $1.0: 1.1: 1.0$; anterior margin of dactylus with 2 setae (Fig. 11I).

Sternal gills (Fig. 12A) on ventral surfaces of pereonites 2-4, respectively.

Coxal gills (Figs. 10E, 11A, C, E, G) on gnathopod 2 and pereopods 3-6.

Brood plates (Figs. 10E, 11A, C, E) slender with numerous setae, on gnathopod 2 and pereopods 3-5.

Peduncles of pleopods 1-3 (Fig. 12B, D, F) lacking marginal setae, outerdistal corners with 2,4 , and 1 seta, respectively. Pleopods $1-3$ with paired retinacula (Fig. 12C, E, G), inner ramus 
318 inner basal margin with 3, 2, and 2 bifid seta (clothes-pin seta), respectively; inner ramus of 319 pleopods 1-3 11-, 9-, and 9-articulate, respectively; outer ramus of pleopods 1-3 13-, 13-, and 320 10-articulate, respectively.

321 Uropod 1 (Fig. 12H) with basofacial seta on peduncle; inner ramus 0.76 times as long as

322

323

324

325

326

327

328

329

330

331

332

333

334

335

336

337

338

339

340

341

342

343

344

345

346

347

348

349

350

351

352

353

354

355

356

357 peduncle, inner and outer margins with 4 and 3 robust setae, respectively, basal part with 3 slender setae; outer ramus 0.6 times as long as inner, with 3 outer marginal robust setae, inner margin bare. Uropod 2 (Fig. 12I) with inner ramus 1.1 times as long as peduncle, outer margin and marginal with 3 and 2 robust setae, respectively; outer ramus 0.7 times as long as inner ramus, inner margin bare and outer margin with 2 robust setae. Uropod 3 (Fig. 12J, K) with peduncle 0.29 times as long as outer ramus; inner ramus absent; outer ramus 2-articulate, proximal article with robust setae, terminal article 0.07 times as long as proximal article, with 3 distal setae.

Telson (Fig. 12L) base laterally concave and shallowly at the top, length 1.33 times as long as wide, cleft for $40.2 \%$ of length, each telson lobe with lateral penicillate setae, apical with 3 robust setae and 1 seta.

Male paratype (NNIBRIV39840). Antenna 1 (Fig. 13A, B) 0.54 times as long as body length, primary flagellum 18-articulate, 1 aesthetasc on some articles. Antenna 2 (Fig. 13C) 0.6 times as long as antenna 1; flagellum 0.46 times as long as peduncular articles 4 and 5 combined, consisting of 7 articles, peduncular article 5 without calceoli and some flagellum with calceolus.

Gnathopod 1 (Fig. 13D, E) carpus with 2 serrate setae on posterodistal corner; palmar margin of propodus with 26 robust setae in 2 rows, some distally notched (Fig. 13F). Gnathopod 2 (Fig. 13G, H) carpus with 2 serrate setae on posterodistal corner; palmar margin of propodus with 20 robust setae in 2 rows, some distally notched (Fig. 13I).

Uropod 1 (Fig. 14A) with basofacial seta on peduncle; inner ramus 0.81 times as long as peduncle; inner margin bare and outer margin with 3 robust setae, basal part with 2 slender setae; outer ramus with 1 marginal robust seta. Uropod 2 (Fig. 14B) with peduncle and inner ramus ratio $1.0: 1.0$; inner ramus 1.2 times as long as outer ramus, distal part with 5 serrate, 3 simple robust setae, 1 simple seta. Uropod 3 (Fig. 14C, D) with outer ramus terminal article 0.1 times as long as proximal article.

Telson (Fig. 14E) length 1.43 times as long as wide, cleft for $45.7 \%$ of length.

Distribution. Known only from the type locality.

Etymology. The specific name is an adjective derived from the name of the cave where the new species was found.

Remarks. Pseudocrangonyx kwangcheonseonensis $\mathbf{s p . ~ n o v . ~ i s ~ m o r p h o l o g i c a l l y ~ m o s t ~ s i m i l a r ~ t o ~}$ P. asiaticus Uéno, 1934 in having 1) eyes completely absent, 2) sternal gills present 3) accessory flagellum of antenna 1 being as long as first article of primary flagellum, 4) antenna 2 longer than half of antenna 1 length, and 5) carpi of gnathopods 1 and 2 with serrate robust setae on posterodistal corner. The new species can be clearly distinguished from $P$. asiaticus by the following characters (features of $P$. asiaticus in parentheses): 1) pereonites 1-7 with (without) short dorsal setae, 2) sternal gills present on pereonites 2-4 (pereonites 2-5), 3) maxilla 1 inner 
358

359

360

361

362

363

364

365

366

367

368

369

370

371

372

373

374

375

376

377

378

379

380

381

382

383

384

385

386

387

388

389

390

391

392

393

394

395

396

plate with 8 (with 4) plumose setae, 4) antenna 1 longer (shorter) than half of the body length, and 5) inner ramus of uropod 1 with 3 (without) outer marginal robust setae.

\section{Pseudocrangonyx hwanseonensis sp. nov.}

urn:1sid:

[New Korean name: Hwan-seon-dong-gul-yeop-sae-u]

(Figs 2C, 15-20)

Pseudocrangonyx asiaticus. -Uéno, 1966: 506-518 (in part), figs. 5O, 7E.

Material examined. Holotype female $(7.5 \mathrm{~mm})$, NNIBRIV35118, collected from Hwanseon Cave $\left(37^{\circ} 19.52^{\prime} \mathrm{N}, 129^{\circ} 1.02^{\prime} \mathrm{E}\right)$, Samcheok-si, Gangwon-do, Korea, on 20 October 2018, by C. W. Lee. Paratypes: 1 female $(7.7 \mathrm{~mm})$, NNIBRIV39836; 1 male $(6.3 \mathrm{~mm})$, NNIBRIV39837, collection data same as that for the holotype.

Diagnosis. Female larger than male; antennal sinus with rounded angle; eyes absent; pereonites 1-6 without short dorsal setae; dorsal margin of urosomite 3 lacking setae; pereonites 2-4 each with 1 pair of sternal gills; antenna 10.53 times as long as body length; antenna 2 with calceoli in both sexes; mandible palp article 3 longer than article 2; maxilla 1 inner plate with 4 plumose setae; maxilla 2 inner plate with oblique inner row of 6 setae; gnathopods 1 and 2, carpi with serrate setae on posterodistal corners in both sexes; palmar margins of propodi of gnathopods 1 and 2 with 13 and 13-15 robust setae, respectively; pleopod peduncles lacking marginal setae, inner margin of inner rami with bifid setae; uropod 1 inner ramus 0.86 times as long as peduncle, inner and outer margins of inner ramus with 3 and 1 robust setae, respectively, basal part of inner ramus with 3 slender setae, outer ramus with 2 marginal robust setae; uropod 2 inner ramus 1.2 times as long as peduncle; inner and outer margins of inner ramus with 2 robust setae, respectively, outer ramus with 2 outer marginal robust setae; uropod 3 terminal article 0.15 time as long as length of proximal article; telson length 1.31 time as long as width, cleft for $36.8 \%$. Description. Female holotype (NNIBRIV35118). Head (Fig. 2C) without dorsal setae; rostrum short; lateral cephalic lobe rounded; antennal sinus shallow with rounded angle; eyes absent. Pereonites 1-6 without short dorsal setae; dorsal margin of pereonite 7 with long setae. Dorsal margins of pleonites 1-3 with long setae (Fig. 2C). Ventral and posterior margins of epimeral plate 1 with 1 and 5 setae, respectively, posteroventral corner with 1 seta; ventral and posterior margins of plate 2 with 4 and 5 setae, respectively, posteroventral corner with 1 seta; ventral and posterior margins of plate 3 with 4 setae, respectively, posteroventral corner with 1 seta (Fig. 2C). Dorsal margin of urosomites 1-2 with setae, urosomite 3 lacking dorsal setae. Anteroventral corner of urosomite 1 with 1 seta, posteroventral corner of urosomite 3 with setae (Fig. 2C).

Antenna 1 (Fig. 15A) 0.53 times as long as body length, peduncular articles 1-3 in length ratio of $1.0: 0.7: 0.4$; accessory flagellum (Fig. 15B) 2-articulate, more than shorter primary flagellar article 1, terminal article with 3 setae and 1 aesthetasc; primary flagellum 16-articulate, 1 aesthetasc on some articles. Antenna 2 (Fig. 15C, D) 0.58 times as long as antenna 1; 
397

398

399

400

401

402

403

404

405

406

407

408

409

410

411

412

413

414

415

416

417

418

419

420

421

422

423

424

425

426

427

428

429

430

431

432

433

434

435

436

peduncular article 5 with 2 calceoli; flagellum 0.53 times as long as peduncular articles 4 and 5 combined, consisting of 7 articles, first 3 each with calceolus.

Upper lip (Fig. 15E) with rounded anterior margin, with fine setae. Mandibles (Fig. 15F, G) left and right incisors 5-dentate; left lacinia mobilis 5-dentate, right lacinia bifid, with many teeth; molar process triturative; accessory setal rows of left and right mandibles with 5 and 4 pectinate setae; palp 3-articulate, article 3 with 5 A-, 12 D-, and 4 E-setae. Lower lip (Fig. 15H) with broad outer lobes with fine setae, mandibular process of outer lobe rounded apically; inner lobes indistinct. Maxilla 1 (Fig. 15I) with inner and outer plates, and palp; inner plate subovate with 4 plumose setae; outer plate subrectangular with 7 serrate teeth apically; palp 2-articulate, longer than outer plate, article 2 with plumose robust seta apically. Maxilla 2 (Fig. 15J) with slender outer plate; oblique inner row of 6 setae on inner plate. Maxilliped (Fig. 16A) with inner and outer plates, and palp; inner plate subrectangular with 6 apical robust setae; outer plate suboval with apical and subapical 3 robust setae, and some medial setae; palp 4-articulate, medial margin of article 2 lined with setae, article 4 with nail.

Gnathopod 1 (Fig. 16B, C) with subquadrate coxa, bearing setae on anterodistal corner to ventral margin, width 1.6 times as long as depth; basis thick and short, anterior margin with 1 seta and some medial setae, posterior margin with 10 long setae; posterodistal corner of carpus with 2 serrate robust setae; propodus stout, subtriangular, palmar margin with 13 robust setae in 2 rows, some distally notched; posterior margin of dactylus dentate (Fig. 16D). Gnathopod 2 (Fig. 16E, F) with subrounded coxa, with setae on its anterior to ventral corners, width 1.3 times as long as depth; basis slender with anterior and posterior margin with 1 seta and 11 long setae, respectively; posterodistal corner of carpus with 3 serrate robust setae; propodus more slender than that of gnathopod 1, palmar margin with 15 robust setae in 2 rows, some distally notched; posterior margin of dactylus dentate (Fig. 16G). Pereopod 3 (Fig. 17A) with subquadrate coxa bearing setae on anterior margin to posteroventral corner, width 1.4 times as long as depth; anterior and posterior margins of basis with setae; merus, carpus, and propodus in length ratio of $1.0: 0.8: 0.8$; posterior margin of dactylus with 2 setae (Fig. 17B). Pereopod 4 (Fig. 17C) with subquadrate coxa bearing setae on anterodistal to posteroventral corners, width 1.4 times as long as depth; basis posterior margin with 9 long setae; merus, carpus, and propodus in length ratio of $1.0: 0.9: 0.8$; posterior margin of dactylus with 2 setae (Fig. 17D). Pereopod 5 (Fig. 17E) with bilobed coxa bearing setae on anterior and posterior lobes; anterior and posterior margins of basis with setae; merus, carpus, and propodus in length ratio of $1.0: 0.9: 1.0$; anterior margin of dactylus with 2 setae (Fig. 17F). Pereopod 6 (Fig. 17G) with weakly bilobed coxa bearing setae on anterior and posterior lobes; anterior and posterior margins of basis with setae; merus, carpus, and propodus in length ratio of $1.0: 0.9: 1.0$; anterior margin of dactylus with 2 setae (Fig. 17H). Pereopod 7 (Fig. 17I) with subtriangular coxa, ventral margin weakly concave, with setae on ventral margin and posterodistal corner; anterior and posterior margins of basis with setae; merus, carpus, and propodus in length ratio of $1.0: 1.0: 1.1$; anterior margin of dactylus with 2 setae (Fig. 17J).

Sternal gills (Fig. 18A) on ventral surfaces of pereonites 2-4, paired. 
437

438

439

440

441

442

443

444

445

446

447

448

449

450

451

452

453

454

455

456

457

458

459

460

461

462

463

464

465

466

467

468

469

470

471

472

473

474

475

476

Coxal gills (Figs. 16E, 17A, C, E, G) on gnathopod 2 and pereopods 3-6.

Brood plates (Figs. 16E, 17A, C, E) slender with numerous setae, on gnathopod 2 and pereopods 3-5.

Peduncles of pleopods 1-3 (Fig. 18B, D, F) lacking marginal setae, outerdistal corners with 2, 2, and 1 setae, respectively. Pleopods 1-3 with paired retinacula (Fig. 18C, E, G), inner ramus inner basal margin with 2, 2, and 1 bifid seta (clothes-pin seta), respectively; inner ramus of pleopods 1-3 9-, 8-, and 7-articulate, respectively; outer ramus of pleopods 1-3 10-, 9-, and 8articulate, respectively.

Uropod 1 (Fig. 18H) with basofacial seta on peduncle; inner ramus 0.86 times as long as peduncle, inner and outer margins with 3 and 1 robust setae, respectively, basal part with 3 slender setae; outer ramus 0.76 times as long as inner, with 2 outer marginal robust setae, inner margin bare. Uropod 2 (Fig. 18I) with inner ramus 1.2 times as long as peduncle, outer margin and marginal with 2 robust setae, respectively; outer ramus 0.73 times as long as inner ramus, inner margin bare and outer margin with 2 robust setae. Uropod 3 (Fig. 18J, K) with peduncle 0.29 times as long as outer ramus; inner ramus absent; outer ramus 2-articulate, proximal article with robust setae, terminal article 0.15 times as long as proximal article, with 4 distal setae.

Telson (Fig. 18L) length 1.31 times as long as wide, cleft for $36.8 \%$ of length, each telson lobe with 2 lateral penicillate setae, apical robust setae and 1 short penicillate seta.

Male paratype (NNIBRIV39837). Antenna 1 (Fig. 19A, B) 0.53 times as long as body length, primary flagellum 14-articulate, 1 aesthetasc on some articles. Antenna 2 (Fig. 19C, D) 0.63 times as long as antenna 1; flagellum 0.58 times as long as peduncular articles 4 and 5 combined, consisting of 7 articles, first 2 each with calceolus.

Gnathopod 1 (Fig. 19E, F) carpus with 2 serrate setae on posterodistal corner; palmar margin of propodus with 13 robust setae in 2 rows, some distally notched (Fig. 19G). Gnathopod 2 (Fig. 19H, I) carpus with 3 serrate setae on posterodistal corner; palmar margin of propodus with 13 robust setae in 2 rows, some distally notched (Fig. 19J).

Uropod 1 (Fig. 20A) with basofacial seta on peduncle; inner ramus 0.79 times as long as peduncle; inner and outer margins with 3 and 1 robust setae, respectively, basal part with 3 slender setae; outer ramus with 2 margin robust setae. Uropod 2 (Fig. 20B) with peduncle 0.90 times as long as inner ramus; inner ramus 1.3 times as long as outer ramus, distal part with 6 serrate, 2 simple robust setae. Uropod 3 (Fig. 20C, D) with outer ramus terminal article 0.22 times as long as proximal article.

Telson (Fig. 20E) length 1.25 times as long as wide, cleft for $40.0 \%$ of length.

Distribution. Known only from the type locality.

Etymology. The specific name is an adjective derived from the name of the cave where the new species was found.

Remarks. Pseudocrangonyx hwanseonensis sp. nov. is morphologically similar to P. asiaticus Uéno, 1934 in having 1) eyes completely absent, 2) pereonites 1-6 without short dorsal setae, 3) urosomite 1 with ventral robust seta, 4) maxilla 1 inner plate with 4 plumose setae, 5) antenna 2 longer than half of antenna 1 length, and 6) carpi of gnathopods 1 and 2 with serrate robust setae 
477 on posterodistal corner. The new species can be clearly distinguished from P. asiaticus by the 478 following characters (features of $P$. asiaticus in parentheses): 1) sternal gills of 1 pair (single) 479 present on each pereonites $2-4$ (pereonites 2-5), 2) maxilla 1 outer plate with 7 (with 5) serrate 480 teeth, 3) antenna 1 longer (shorter) than as long as body length half, and 4) uropod 3 terminal 481 article shorter (longer) than adjacent robust setae.

482

483 Key to the species of Korean Pseudocrangonyx.

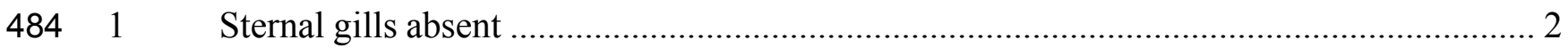

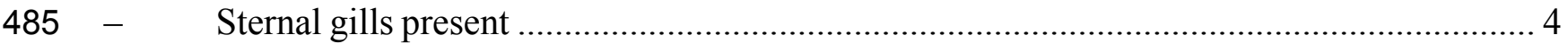

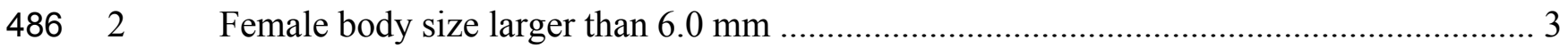

487 - $\quad$ Female body size smaller than $6.0 \mathrm{~mm}$............................... P. daejeonensis Lee et al., 2018

4883 Uropod 3 terminal article longer than adjacent robust setae ...... P. minutus Jung et al., 2020

489 - $\quad$ Uropod 3 terminal article shorter than adjacent robust setae ......P. wonkimi Lee et al., 2020

4904 Carpus of gnathopod with serrate robust setae on posterodistal corner ……....................... 5

491 - Carpus of gnathopod without serrate robust setae on posterodistal corner

492 P. coreanus Uéno, 1966

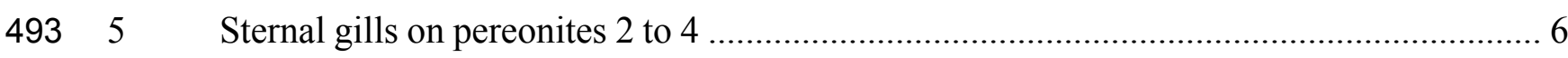

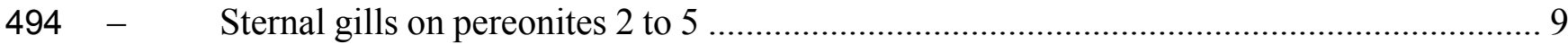

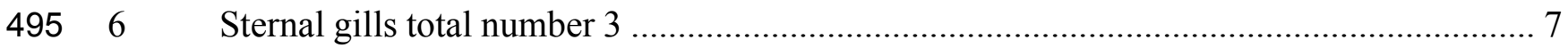

496 - Sternal gills total number 6 .................................................. P. hwanseonensis sp. nov.

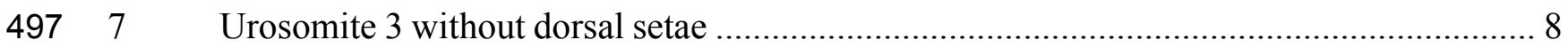

498 - $\quad$ Urosomite 3 with dorsal setae .................................................... P. deureunensis sp. nov.

4998 Accessory flagellum of antenna 1 exceeding first article of primary flagellum

500

501

P. kwangcheonseonensis

sp.

502

$503-$

nov.

504

505

P. joolaei Lee et al., 2020

$5069 \quad$ Maxilla 1 inner plate with less than 7 plumose setae ………………........................ 10

507 - $\quad$ Maxilla 1 inner plate with 7 plumose setae ............................. P. villosus Jung et al., 2020

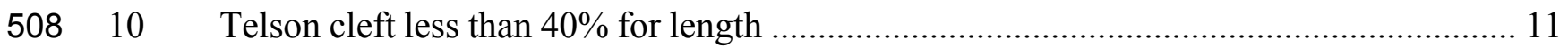

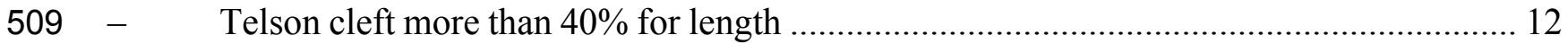

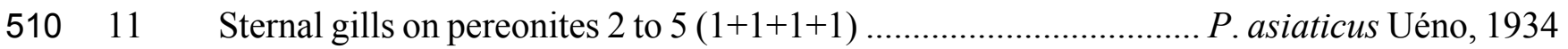

511 - Sternal gills on pereonites 2 to $5(1+1+0+1)$............................ P. crassus Jung et al., 2020

51212 Uropod 2 outer ramus with 2 inner marginal robust setae ...... P. gracilipes Jung et al., 2020

513 - Uropod 2 outer ramus without inner marginal robust setae ..... P. concavus Jung et al., 2020

514

515 Molecular Analyses. The uncorrected COI $p$-distance among the species of the genus

516 Pseudocrangonyx in Korean caves is shown in Table 2; this divergence was calculated based on 
517 the 657 aligned positions from the data set. The range of interspecific variation was $11.7-17.0 \%$.

518 However, the maximum intraspecific variation was $0.2 \%$ within each species. In the

519 phylogenetic analyses (Fig. 21), the topologies of the BI and ML trees were almost identical.

520 Results of the present analyses showed that the species of the genus Pseudocrangonyx,

521 inhabiting individual caves, were distinct new species.

522

523

\section{Discussion}

524 The three new species described in this paper are similar to P. asiaticus Uéno, 1934 in

525 morphology, and they share the following characteristics: relatively large body size (about 8.0

$52610.0 \mathrm{~mm}$ ), completely absent eyes, presence of basal setae on urosomite 1, present sternal gills,

527 and carpi of gnathopods 1 and 2 with serrate robust setae on the posterodistal corner. However,

528 the three new species have following characteristics that distinguished them as distinct new

529 species: 1) P. deureunensis sp. nov., urosomite 3 with dorsal setae; 2) P. kwangcheonseonensis

530 sp. nov., maxilla 1 inner plate with 8 plumose setae, telson base laterally concave, and shallow at

531 the top; and 3) P. hwanseonensis sp. nov., sternal gills of 1 pair present on each pereonites 2-4.

532 Furthermore, the COI genetic distance among the three species showed significant differentiation

$533(12.5-13.4 \%)$ that was sufficient to designate the species as distinct, which was confirmed by a

534 previous study (12-20\%) on the genus Pseudocrangonyx (Zhao \& Hou 2017).

535 Most geographically separated subterranean species are likely to be independent in origin due to

536 their poor dispersal and small ranges (Trontelj et al. 2009; Trontelj et al. 2012). Likewise, our

537 molecular phylogenetic analyses revealed that the species within the genus Pseudocrangonyx

538 endemic to the Korean Peninsula caves formed a monophyletic clade (Fig. 21: in gray box),

539 suggesting that the genus Pseudocrangonyx inhabits groundwater environments where dispersal

540 is limited, such as a cave, and that they may have an independent origin in each habitat. A

541 previous study (Lee et al. 2020) found that P.joolaei Lee et al., 2020 and P. akatsukai

542 Tomikawa \& Nakano, 2018 formed a clade. However, our results showed that $P$. joolaei has a

543 closer relationship with the Korean cave Pseudocrangonyx species. Additionally, our

544 phylogenetic analyses showed that all Korean cave Pseudocrangonyx species were a same clade,

545 but the Japanese $P$. akatsukai was in a different clade. This means that rather than forming a

546 clade with the Japanese species, the Korean cave Pseudocrangonyx species may share a single

547 lineage with $P$. asiaticus sensu stricto, which is geographically adjacent and morphologically

548 similar. Unfortunately, we could not obtain molecular data for P. asiaticus Uéno, 1934, and it is

549 unclear whether $P$. asiaticus sensu stricto inhabit the Korean Peninsula. Additional molecular

550 data for $P$. asiaticus should be examined in order to confirm the presence of $P$. asiaticus sensu

551 stricto and explore the true species diversity of Pseudocrangonyx amphipods inhabiting the

552 Korean Peninsula.

553 Ultimately, it is important to study the biogeography of pseudocrangonyctids in order to

554 better understand the origin and evolution of subterranean amphipod fauna in the Far East

555 (Sidorov \& Holsinger 2007). Further molecular phylogenetic analyses of Pseudocrangonyx are

Peer) reviewing PDF | (2020:10:54037:1:0:NEW 22 Dec 2020) 
556 essential for enhancing the understanding of subterranean Crangonyctoidea species diversity and 557 evolutionary history in Far East Asia.

558

\section{Conclusions}

560 This study described three new species described found in caves in Korea. Two new species of

561

562

563

564

565

566

567

568

569

570

\section{1}

572

573

574

575

576

577

578

579

580

581

582

583

584

585

586

587

588

589

590

591

592

593 them were found from caves treated as the morphological variants of $P$. asiaticus Uéno, 1934. The other new species was found from a cave with no former records of the genus Pseudocrangonyx. These new species may receive a unique species status within the genus Pseudocrangonyx based on our morphological examination and molecular analyses. These results suggest that the genus Pseudocrangonyx may have greater species diversity in the Korean Peninsula than previously believed. Although we failed to obtain molecular data of the originally described $P$. asiaticus, obtaining those data in future studies may make it possible to determine the true species diversity of the subterranean amphipod Pseudocrangonyx in Far East Asia including the Korean Peninsula.

\section{Acknowledgements}

We are grateful to the Korean Society of Cave Environmental Science (Daejeon, Korea), especially Mr. Yong Gun Choi for their continued support and assistance.

\section{References}

Akatsuka, K. \& Komai, T. 1922. Pseudocrangonyx, a new genus of subterranean amphipods from Japan. Annotationes Zoologicae Japonenses, 10: 119-126.

Folmer, O., Black, M., Hoeh, W., Lutz, R. \& Vrijenhoek, R. 1994. DNA primers for amplification of mitochondrial cytochrome $c$ oxidase subunit I from diverse metazoan invertebrates. Molecular Marine Biology and Biotechnology, 3: 294-299.

Holsinger, J.R. 1989. Allocrangonyctidae and Pseudocrangonyctidae, two new families of Holarctic subterranean amphipod crustaceans (Gammaridea), with comments on their phylogenetic and zoogeographic relationships. Proceedings of the Biological Society of Washington, 102: 947-959.

Holsinger, J.R. 1993. Biodiversity of subterranean amphipod crustaceans: global patterns and zoogeographic implications. Journal of Natural History, 27: 821-835. doi:10.1080/00222939300770501.

Holsinger, J.R. 1994. Pattern and process in the biogeography of subterranean amphipods. Hydrobiologia, 287: 131-145. doi:10.1007/Bf00006902.

Hou, Z. \& Li, S. 2010. Intraspecific or interspecific variation: delimitation of species boundaries within the genus Gammarus (Crustacea, Amphipoda, Gammaridae), with description of four new species. Zoological Journal of the Linnean Society, 160: 215-253. doi:10.1111/j.10963642.2009.00603.x. 
594 Hou, Z., Fu, J. \& Li, S. 2007. A molecular phylogeny of the genus Gammarus (Crustacea:

595

596

597

598

599

600

601

602

603

604

605

606

607

608

609

610

611

612

613

614

615

616

617

618

619

620

621

622

623

624

625

626

627

628

629

630

631

632

633

Amphipoda) based on mitochondrial and nuclear gene sequences. Molecular Phylogenetics and Evolution, 45: 596-611. doi:10.1016/j.ympev.2007.06.006.

Jones, R., Culver, D.C. \& Kane, T.C. 1992. Are parallel morphologies of cave organisms the result of similar selection pressures?. Evolution, 46: 353-365. doi:10.1111/j.15585646.1992.tb02043.x.

Jung, T.W., Kim, J.G., Kim, M.S. \& Yoon, S.M. 2020. Five new subterranean amphipods of the genus Pseudocrangonyx from Korea (Crustacea, Amphipoda, Pseudocrangonyctidae). ZooKeys, 970: 1-50. doi:10.3897/zookeys.970.55035

Katoh, K. \& Standley, D.M. 2013. MAFFT multiple sequence alignment software version 7: improvements in performance and usability. Molecular Biology and Evolution, 30: 772-780. doi: $10.1093 / \mathrm{molbev} / \mathrm{mst} 010$.

Kornobis, E., Pálsson, S., Sidorov, D.A., Holsinger, J.R. \& Kristjánsson, B.K. 2011. Molecular taxonomy and phylogenetic affinities of two groundwater amphipods, Crangonyx islandicus and Crymostygius thingvallensis, endemic to Iceland. Molecular Phylogenetics and Evolution, 58: 527-539. doi:10.1016/j.ympev.2010.12.010.

Kumar, S., Stecher, G., Li, M., Knyaz, C. \& Tamura, K. 2018. MEGA X: molecular evolutionary genetics analysis across computing platforms. Molecular Biology and Evolution, 35: 15471549. doi:10.1093/molbev/msy096.

Lanfear, R., Frandsen, P.B., Wright, A.M., Senfeld, T. \& Calcott, B. 2017. PartitionFinder 2: New methods for selecting partitioned models of evolution for molecular and morphological phylogenetic analyses. Molecular Biology and Evolution, 34: 772-773. doi:10.1093/molbev/msw260.

Lee, C.-W., Tomikawa, K. \& Min, G.-S. 2020. A new cave amphipod, Pseudocrangonyx wonkimi sp. nov. (Crustacea, Amphipoda, Pseudocrangonyctidae), from the Korean Peninsula. ZooKeys, 960: 1-15.

Lee, C.-W., Tomikawa, K., Nakano, T. \& Min, G.-S. 2018. A new species of the genus Pseudocrangonyx (Crustacea, Amphipoda, Pseudocrangonyctidae) from Korea. ZooKeys, 735: 27-44. doi: 10.3897/zookeys.735.21697

Lee, C.-W., Tomikawa, K., Nakano, T. \& Min G.-S. 2020. A new species of the genus Pseudocrangonyx (Crustacea: Amphipoda: Pseudocrangonyctidae) from Simbok Cave, Korea. Zootaxa, 4731: 321-334. doi:10.11646/zootaxa.4731.3.2.

Lefébure, T., Douady, C.J., Gouy, M., Trontelj, P., Briolay, J. \& Gibert, J. 2006. Phylogeography of a subterranean amphipod reveals cryptic diversity and dynamic evolution in extreme environments. Molecular Ecology, 15: 1797-1806. doi:10.1111/j.1365-294X.2006.02888.x.

Rambaut, A., Drummond, A.J., Xie, D., Baele, G. \& Suchard, M.A. 2018. Posterior summarization in Bayesian phylogenetics using Tracer 1.7. Systematic Biology, 67: 901-904. doi:10.1093/sysbio/syy032.

Ronquist, F., Teslenko, M., van der Mark, P., Ayres, D.L., Darling, A., Höhna, S., Larget, B., Liu, L., Suchard, M.A. \& Huelsenbeck, J.P. 2012. MrBayes 3.2: efficient Bayesian 
634

635

636

637

638

639

640

641

642

643

644

645

646

647

648

649

650

651

652

653

654

655

656

657

658

659

660

661

662

663

664

665

666

667

668

669

670

phylogenetic inference and model choice across a large model space. Systematic Biology, 61: 539-542. doi:10.1093/sysbio/sys029.

Sidorov, D. \& Holsinger, J.R. 2007. Procrangonyx stygoedincus, a new species of subterranean amphipod (Pseudocrangonyctidae) from the far east of Russia, with remarks on biogeographic relationships. Crustaceana, 80: 417-430. doi:10.1163/156854007780440984.

Stamatakis, A. 2014. RAxML version 8: a tool for phylogenetic analysis and post-analysis of large phylogenies. Bioinformatics, 30: 1312-1313. doi:10.1093/bioinformatics/btu033.

Stock, J.H. 1974. The systematics of certain Ponto-Caspian Gammaridae (Crustacea, Amphipoda). Mitteilungen aus dem Hamburgischen Zoologischen Museum und Institut, 70: 75-95.

Tomikawa, K. \& Nakano, T. 2018. Two new subterranean species of Pseudocrangonyx Akatsuka \& Komai, 1922 (Amphipoda: Crangonyctoidea: Pseudocrangonyctidae), with an insight into groundwater faunal relationships in western Japan. Journal of Crustacean Biology, 38: 460-474. doi:10.1093/jcbiol/ruy031.

Tomikawa, K., Nakano, T., Sato, A., Onodera, Y. \& Ohtaka, A. 2016. A molecular phylogeny of Pseudocrangonyx from Japan, including a new subterranean species (Crustacea, Amphipoda, Pseudocrangonyctidae). Zoosystematics and Evolution, 92, 187. doi:10.3897/zse.92.10176

Trontelj, P., Blejec, A. \& Fišer, C. 2012. Ecomorphological convergence of cave communities. Evolution, 66: 3852-3865. doi:10.1111/j.1558-5646.2012.01734.x.

Trontelj, P., Douady, C.J., Fišer, C., Gibert, J., Gorički, Š., Lefébure, T., Sket, B. \& Zakšek, V. 2009. A molecular test for cryptic diversity in ground water: how large are the ranges of macro-stygobionts? Freshwater Biology, 54: 727-744. doi:10.1111/j.13652427.2007.01877.x.

Uéno, M. 1934. Subterranean Crustacea from Kwantung. Annotationes zoologicae Japonenses, 14: $445-450$.

Uéno, M. 1940. Freshwater amphipoda of Manchoukuo. Kwantung Prefectural Office Department of Public Works (Ed), Report of the Limnobiological Survey of Kwantung and Manchoukuo Kwantung Prefectural Office Department of Public Works, Ryojun: 311-322. Uéno, M. 1966. Results of the speleological survey in South Korea 1966 II. Gammarid Amphipoda found in subterranean waters of South Korea. Bulletin of the National Science Museum, 9: 501-535.

Väinölä, R., Witt, J., Grabowski, M., Bradbury, J.H., Jazdzewski, K. \& Sket, B. 2007. Global diversity of amphipods (Amphipoda; Crustacea) in freshwater. In: Freshwater Animal Diversity Assessment, pp. 241-255. Springer.

Zhao, S. \& Hou, Z. 2017. A new subterranean species of Pseudocrangonyx from China with an identification key to all species of the genus (Crustacea, Amphipoda, Pseudocrangonyctidae). ZooKeys, 647: 1-22. doi:10.3897/zookeys.647.11192. 


\section{Table 1 (on next page)}

Data used for molecular analyses. Sequences marked with an asterisk were obtained for the first time in the present study. 
1 Table 1. Data used for molecular analyses. Sequences marked with an asterisk were obtained for

2 the first time in the present study.

\begin{tabular}{|c|c|c|c|c|}
\hline \multirow{2}{*}{ Species } & \multirow{2}{*}{ Voucher or isolate } & \multirow{2}{*}{$\begin{array}{l}\text { Locality or Country } \\
\text { (Habitat) }\end{array}$} & \multicolumn{2}{|c|}{ GenBank No. } \\
\hline & & & $28 \mathrm{~S}$ & $\mathrm{COI}$ \\
\hline \multicolumn{5}{|l|}{ Genus Pseudocrangonyx } \\
\hline \multirow{3}{*}{ P. deureunensis sp. nov. } & NNIBRIV39838 & \multirow{3}{*}{$\begin{array}{c}\text { Bonghwa, Korea } \\
\text { (Cave) }\end{array}$} & MW026427* & MW026424* \\
\hline & NNIBRIV39835 & & & MW026425* \\
\hline & NNIBRIV39839 & & & MW026426* \\
\hline \multirow{3}{*}{ P. kwangcheonseonensis sp. nov. } & NNIBRIV35120 & \multirow{3}{*}{$\begin{array}{c}\text { Pyeongchang, } \\
\text { Korea } \\
\text { (Cave) }\end{array}$} & MW026433* & MW026430* \\
\hline & NNIBRIV39840 & & & MW026431* \\
\hline & NNIBRIV39841 & & & MW026432* \\
\hline \multirow{3}{*}{ P. hwanseonensis sp. nov. } & NNIBRIV35118 & \multirow{3}{*}{$\begin{array}{c}\text { Samcheok, Korea } \\
\text { (Cave) }\end{array}$} & MW026439* & MW026436* \\
\hline & NNIBRIV39836 & & & MW026437* \\
\hline & NNIBRIV39837 & & & MW026438* \\
\hline \multirow{2}{*}{ P.wonkimi } & NNIBRIV35119 & \multirow{2}{*}{$\begin{array}{l}\text { Hampyeong, Korea } \\
\text { (Cave) }\end{array}$} & MT316536 & MT316534 \\
\hline & NNIBRIV36158 & & & MT316535 \\
\hline \multirow{2}{*}{ P.joolaei } & NNIBRIV21629 & \multirow{2}{*}{$\begin{array}{c}\text { Goesan, Korea } \\
\text { (Cave) }\end{array}$} & \multirow[t]{2}{*}{ LC467007 } & LC467001 \\
\hline & NNIBRIV21630 & & & LC467002 \\
\hline P. daejeonensis & NNIBRIV1 & $\begin{array}{c}\text { Daejeon, Korea } \\
\text { (Interstitial water) }\end{array}$ & LC322136 & LC322137 \\
\hline P. akatsukai & KUZ Z1967 (G1277) & Yamaguchi, Japan & LC171506 & LC171507 \\
\hline P. komaii & KUZ Z1976 (G1297) & Yamaguchi, Japan & LC171541 & LC171542 \\
\hline P. gudariensis & NSMT-Cr 24605 & Aomori, Japan & LC171498 & LC171499 \\
\hline P. yezonis & KUZ Z1970 (G1280) & Hokkaido, Japan & LC171518 & LC171519 \\
\hline P. uenoi & KUZ Z1964 (G405) & Shiga, Japan & LC171491 & LC171492 \\
\hline P. elegantulus & IZCAS I-A1602-2 & China & KY436646 & KY436647 \\
\hline P. holsingeri & & Russian Far East & KJ871679 & KF153111 \\
\hline P. korkishkoorum & B1 & Russian Far East & KJ871678 & KF153107 \\
\hline P. korkishkoorum & N1 & Russian Far East & KJ871676 & KF153105 \\
\hline P. tiunovi & & Russian Far East & KJ871674 & KF153110 \\
\hline P.febras & & Russian Far East & & KF153114 \\
\hline P. susanaensis & & Russian Far East & & KF153113 \\
\hline P. sympatricus & & Russian Far East & & KF153112 \\
\hline \multicolumn{5}{|l|}{ Outgroup Genus Crangonyx } \\
\hline C. floridanus & G1322 & Chiba, Japan & LC171549 & LC171550 \\
\hline
\end{tabular}




\section{Table 2 (on next page)}

Intra- and interspecific variation calculated from COI of Korean cave Pseudocrangonyx. 
1 Table 2. Intra- and interspecific variation calculated from COI of Korean cave Pseudocrangonyx.

\begin{tabular}{|c|c|c|c|c|c|c|}
\hline \multirow{2}{*}{ Species name } & \multirow{2}{*}{ Intraspecific $(\%)$} & \multicolumn{5}{|c|}{ Interspecific (\%) } \\
\hline & & 1 & 2 & 3 & 4 & 5 \\
\hline P. deureunensis sp. nov. & 0.2 & - & & & & \\
\hline P. kwangcheonseonensis sp. nov. & 0.2 & $13.2-13.4$ & - & & & \\
\hline P. hwanseonensis sp. nov. & - & $13.2-13.4$ & $12.5-12.6$ & - & & \\
\hline P. wonkimi Lee et al., 2020 & - & $16.9-17.0$ & $13.9-14.0$ & 14.6 & - & \\
\hline P.joolaei Lee et al., 2020 & 0.2 & $15.2-15.4$ & $14.8-15.1$ & $11.7-11.9$ & $14.9-15.1$ & - \\
\hline
\end{tabular}

2 
Figure 1

The collection locality of the specimens examined in this study.

(A) Deureune cave; (B) Kwangcheonseon cave; (C) Hwanseon cave. 


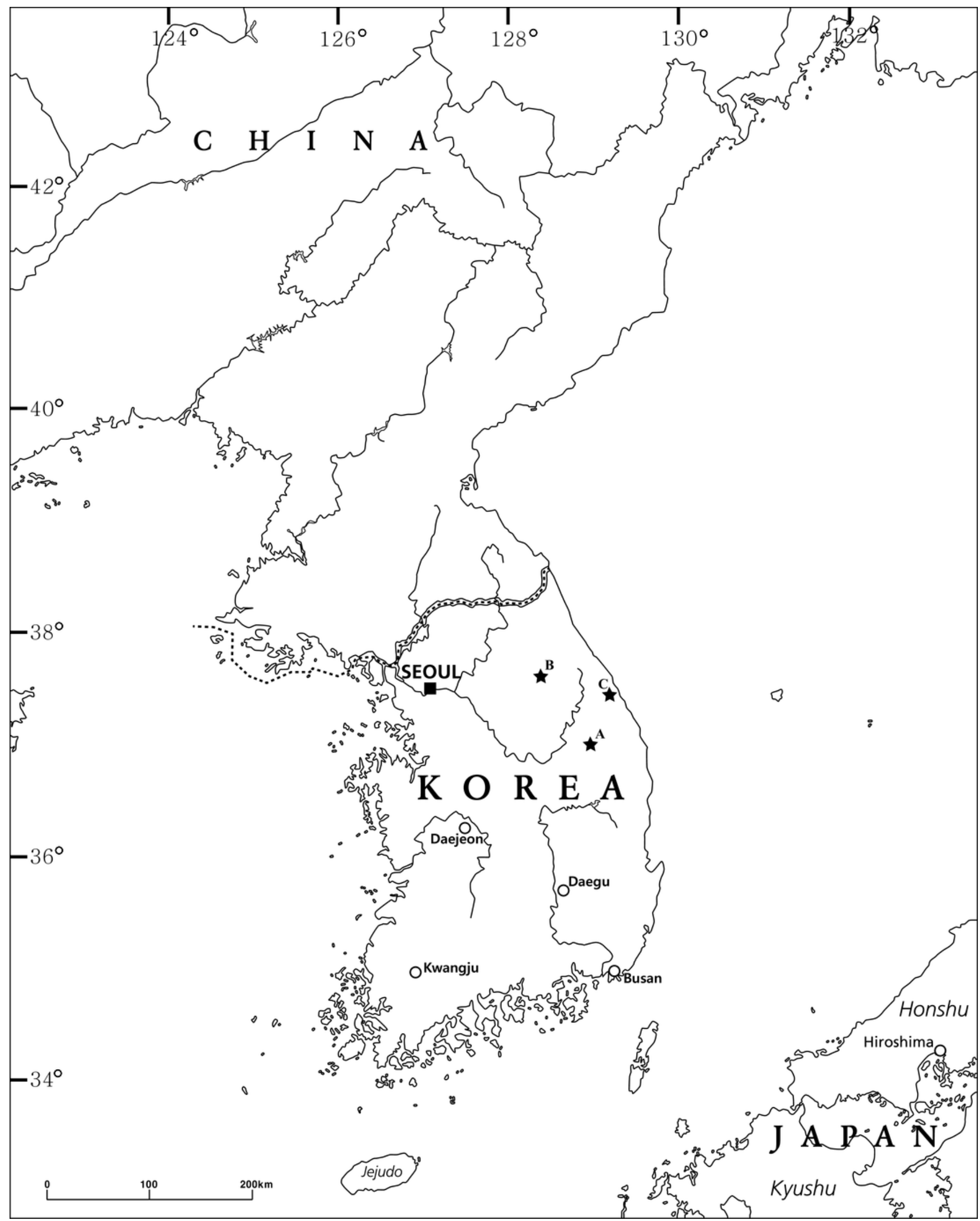


Figure 2

Habitus of three new species.

(A) Paratype of Pseudocrangonyx deureunensis sp. nov., lateral view; (B) Holotype of Pseudocrangonyx kwangcheonseonensis sp. nov., lateral view; (C) Holotype of Pseudocrangonyx hwanseonensis sp. nov., lateral view. 

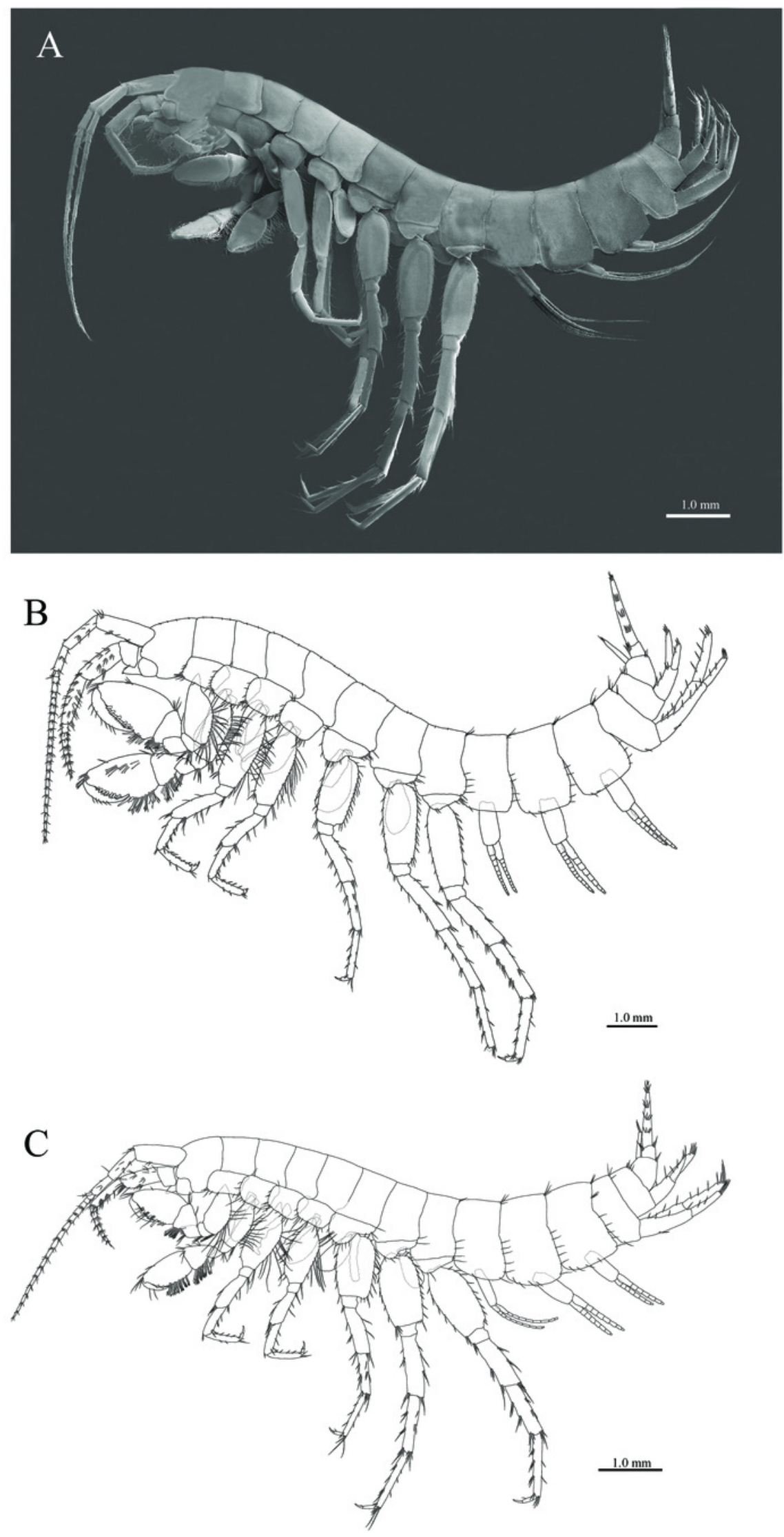


\section{Figure 3}

Holotype of Pseudocrangonyx deureunensis sp. nov. (NNIBRIV39838).

(A) Head, lateral view; (B) Epimeral plates 1-3 and urosomites 1-3, lateral view; (C) Antenna 1, medial view; (D) Accessory flagellum of antenna 1, medial view; (E) Antenna 2, medial view; (F) Calceolus of antenna 2, medial view; (G) Upper lip, posterior view; (H) Left mandible, medial view; (I) Incisor, lacinia mobilis, and molar process of right mandible, medial view; (J) Incisor and lacinia mobilis of left mandible, medial view; (K) Lower lip, ventral view; (L) Maxilla 1, dorsal view. 


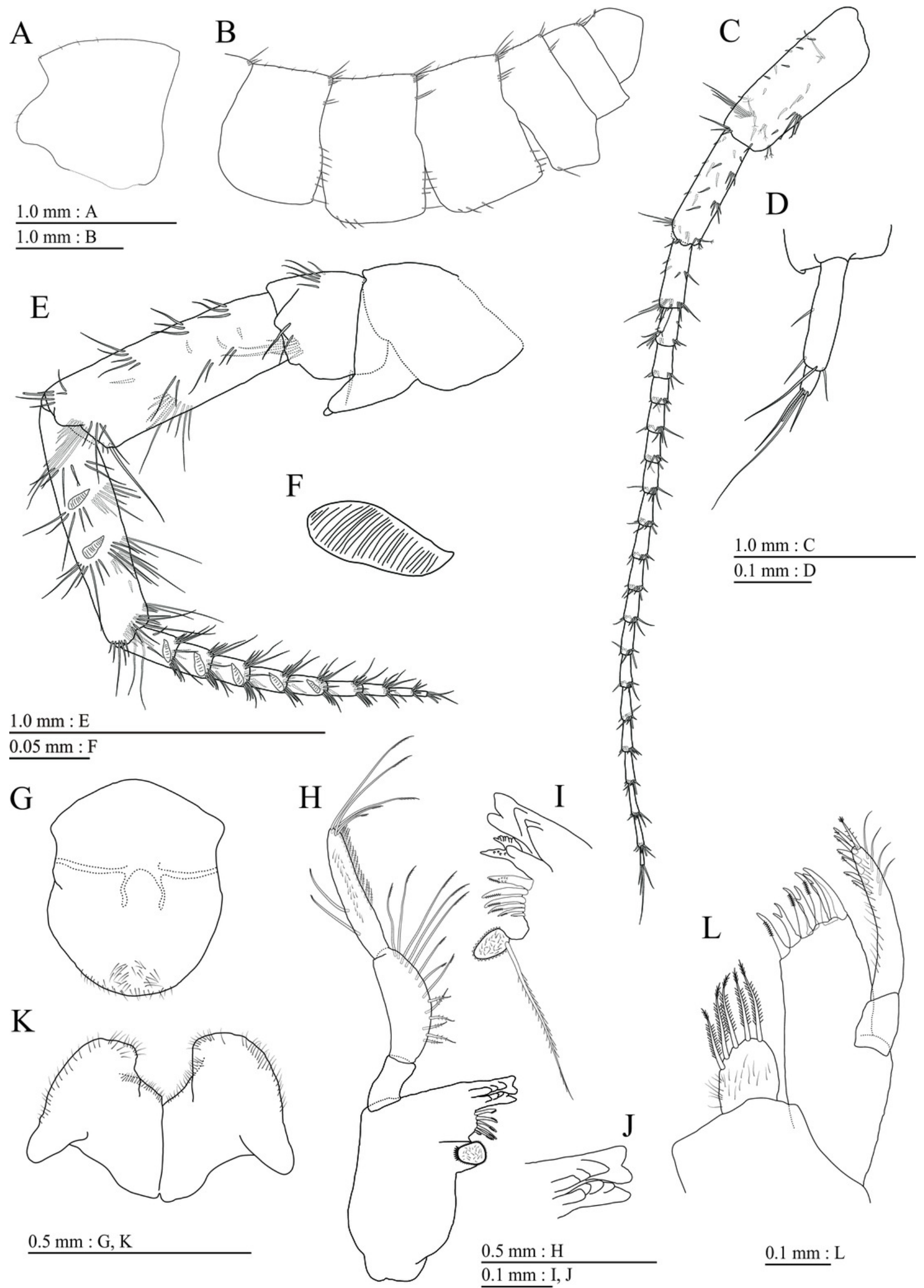




\section{Figure 4}

Holotype of Pseudocrangonyx deureunensis sp. nov. (NNIBRIV39838).

(A) Maxilla 2, dorsal view; (B) Maxilliped, dorsal view; (C) Apical setae on inner plate of

maxilliped, dorsal view; (D) Gnathopod 1, medial view; (E) Serrate setae on posterodistal

corner of carpus of gnathopod 1, lateral view; (F) Palmar margin of propodus and dactylus of gnathopod 1, medial view; (G) Gnathopod 2, medial view; (H) Serrate setae on posterodistal corner of carpus of gnathopod 2, lateral view; (I) Palmar margin of propodus and dactylus of gnathopod 2, medial view. 


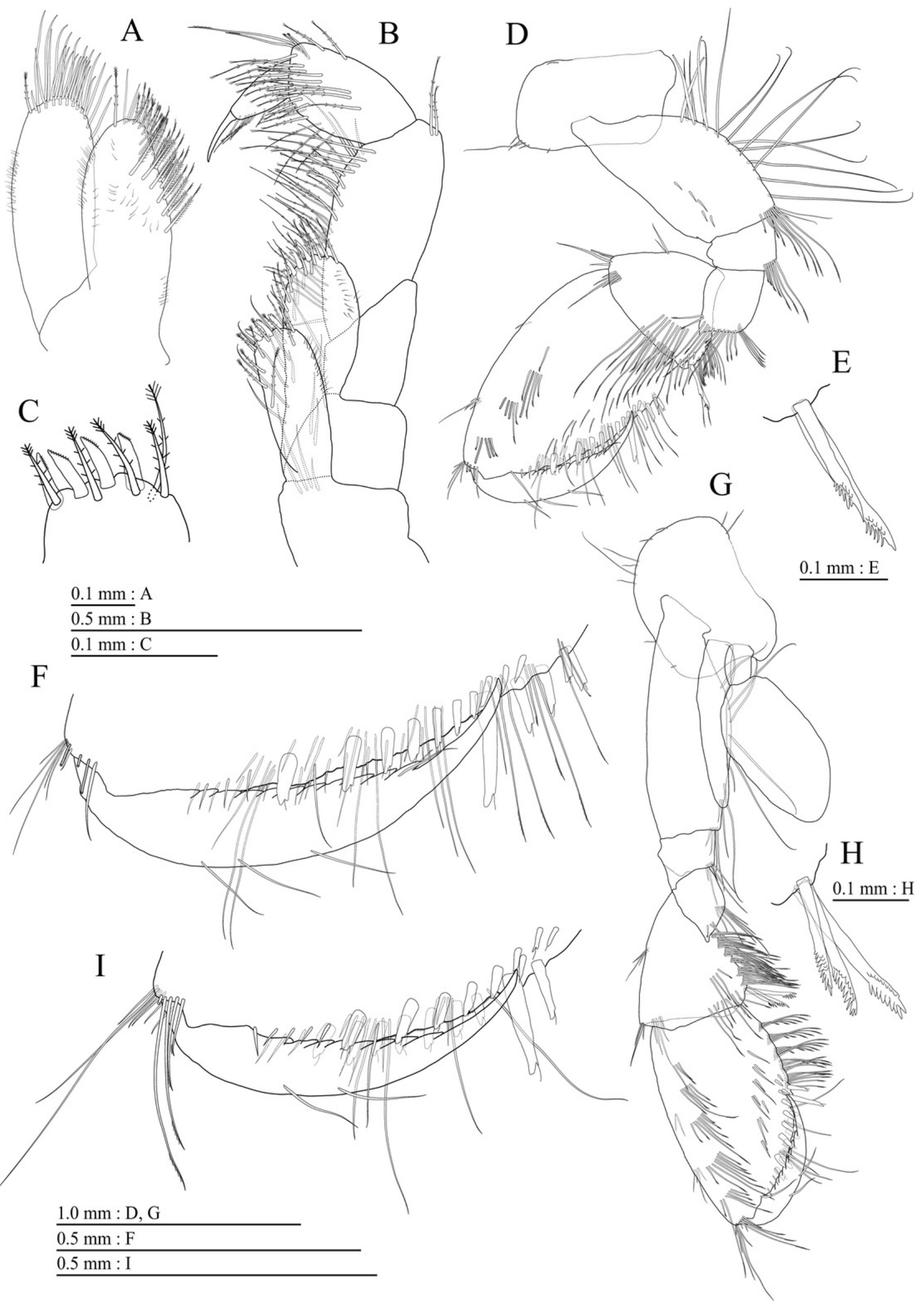




\section{Figure 5}

Holotype of Pseudocrangonyx deureunensis sp. nov. (NNIBRIV39838).

(A) Pereopod 3, medial view; (B) Dactylus of pereopod 3, medial view; (C) Pereopod 4, medial view; (D) Dactylus of pereopod 4, medial view; (E) Pereopod 5, medial view; (F) Dactylus of pereopod 5, medial view; (G) Pereopod 6, medial view; (H) Dactylus of pereopod 6, medial view; (I) Pereopod 7, medial view; (J) Dactylus of pereopod 7, medial view.

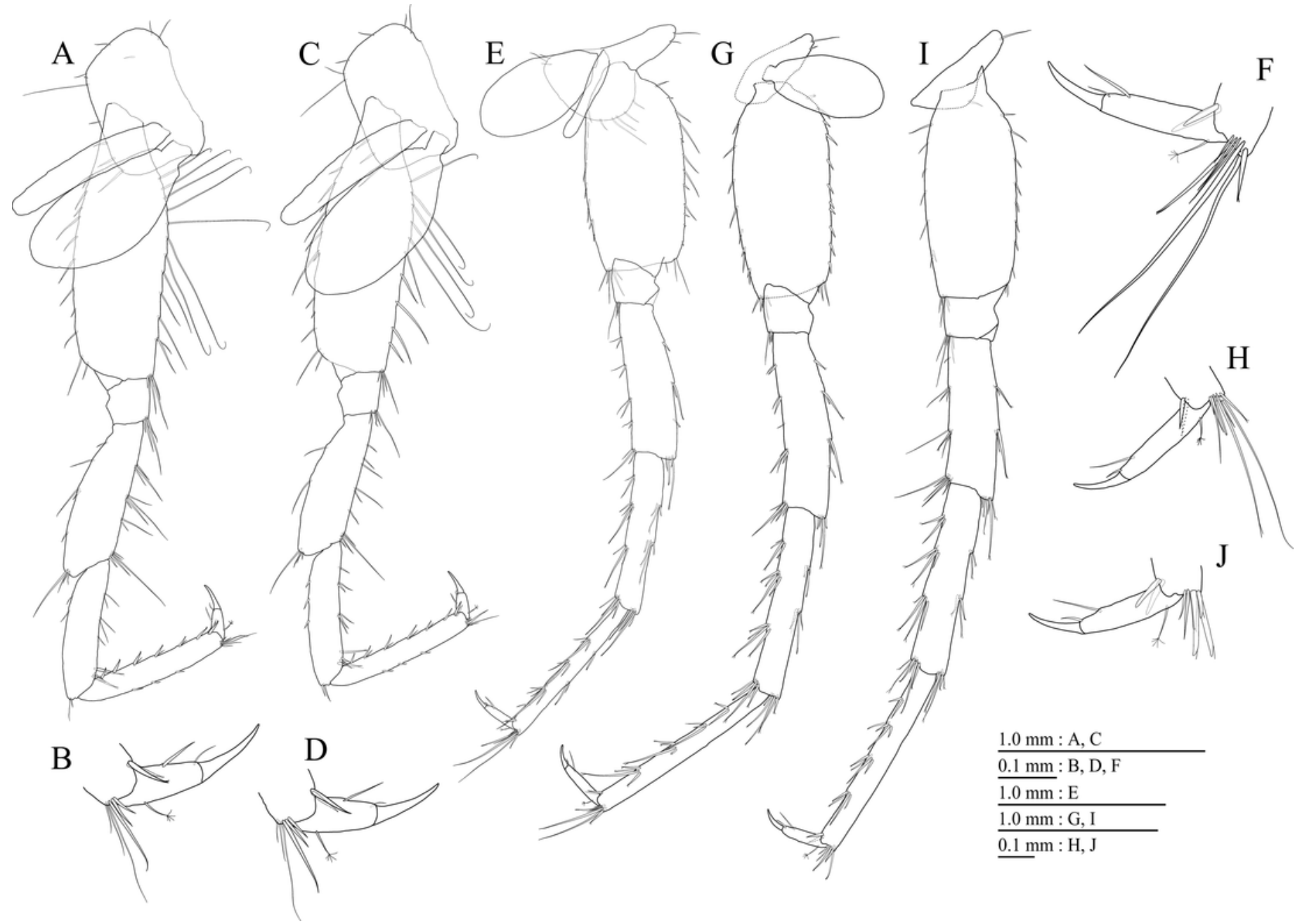




\section{Figure 6}

Holotype of Pseudocrangonyx deureunensis sp. nov. (NNIBRIV39838).

(A) Sternal gills on pereonites 2-4, lateral view; (B) Pleopod 1, lateral view; (C) Retinacula on peduncle of pleopod 1, lateral view; (D) Pleopod 2, lateral view; (E) Retinacula on peduncle of pleopod 2, lateral view; (F) Pleopod 3, lateral view; (G) Retinacula on peduncle of pleopod 3, lateral view; (H) Uropod 1, dorsal view; (I) Uropod 2, dorsal view; (J) Uropod 3, dorsal view; (K) Telson, dorsal view. 

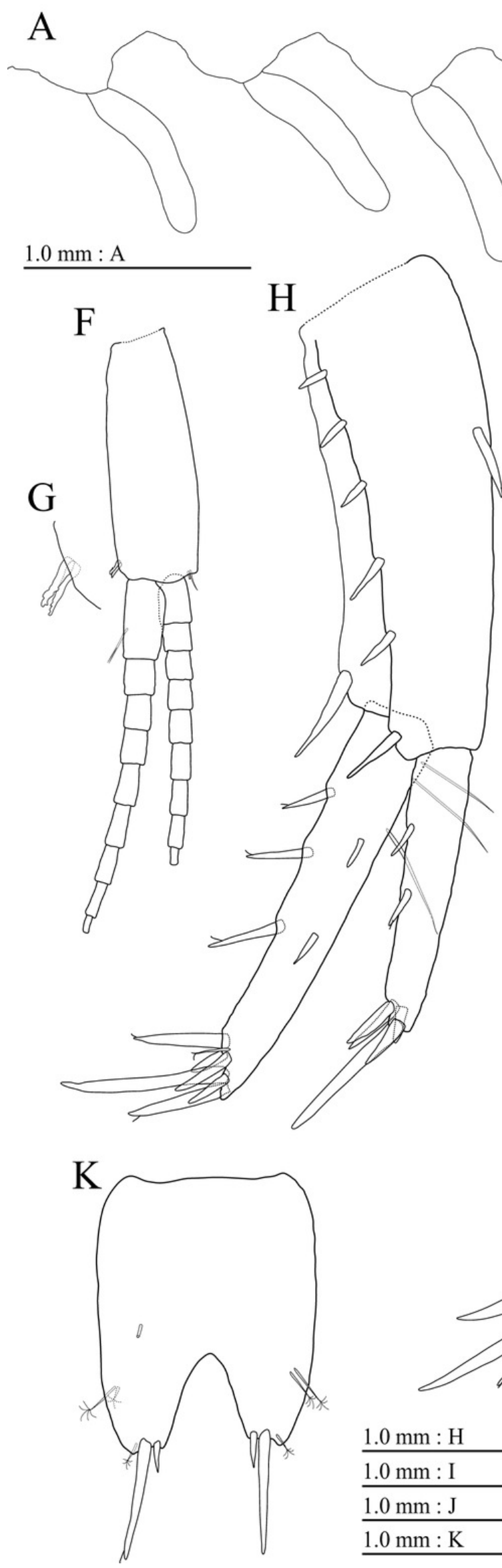

$1.0 \mathrm{~mm}: \mathrm{H}$

$1.0 \mathrm{~mm}:$

$1.0 \mathrm{~mm}: \mathrm{J}$

$1.0 \mathrm{~mm}: \mathrm{K}$
B
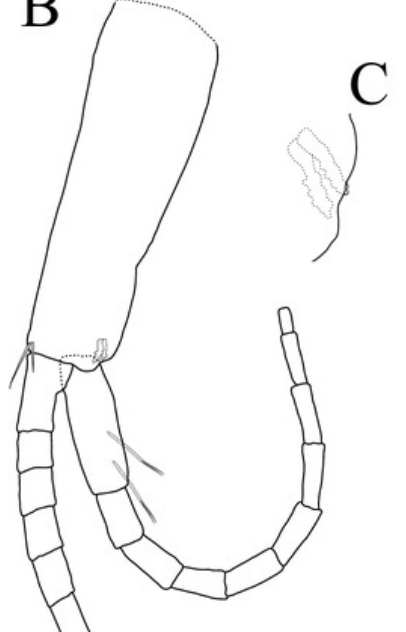

E

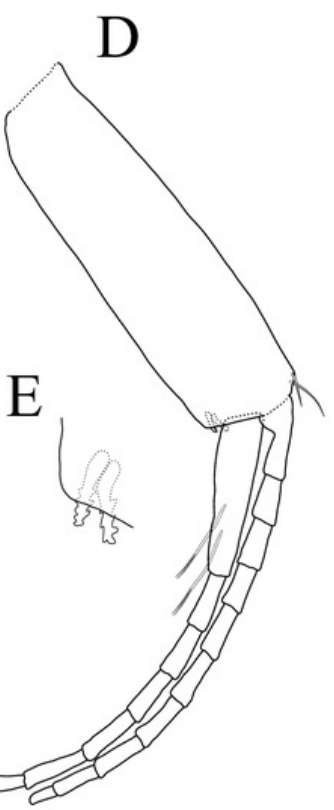

$1.0 \mathrm{~mm}: \mathrm{B}, \mathrm{D}, \mathrm{F}$

$0.05 \mathrm{~mm}: \mathrm{C}, \mathrm{E}, \mathrm{G}$

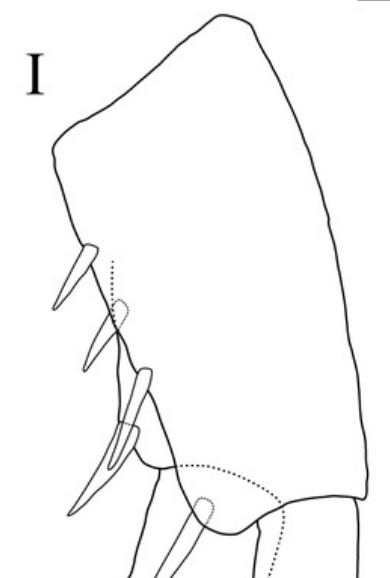




\section{Figure 7}

Paratype of Pseudocrangonyx deureunensis sp. nov. (NNIBRIV39839).

(A) Antenna 1, medial view; (B) Accessory flagellum of antenna 1, medial view; (C) Antenna 2, medial view; (D) Calceolus of antenna 2, medial view; (E) Gnathopod 1, medial view; (F) Palmar margin of propodus and dactylus of gnathopod 1, medial view; (G) Gnathopod 2, medial view; (H) Palmar margin of propodus and dactylus of gnathopod 2, medial view. 


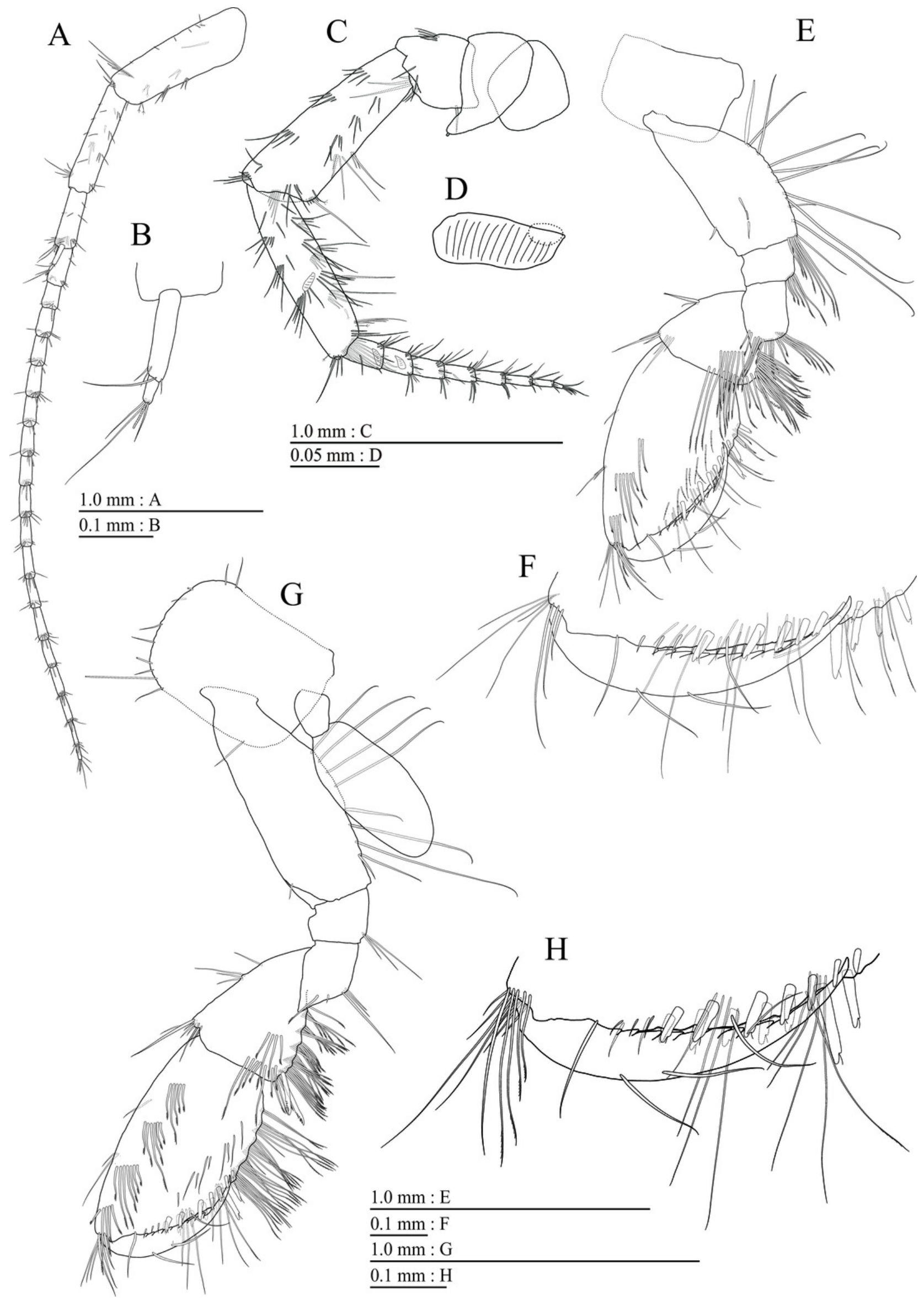




\section{Figure 8}

Paratype of Pseudocrangonyx deureunensis sp. nov. (NNIBRIV39839).

(A) Uropod 1, dorsal view; (B) Uropod 2, ventral view; (C) Distal robust seta on inner ramus of uropod 2, ventral view; (D) Uropod 3, dorsal view; (E) Terminal article of uropod 3, dorsal view; (F) Telson, dorsal view.
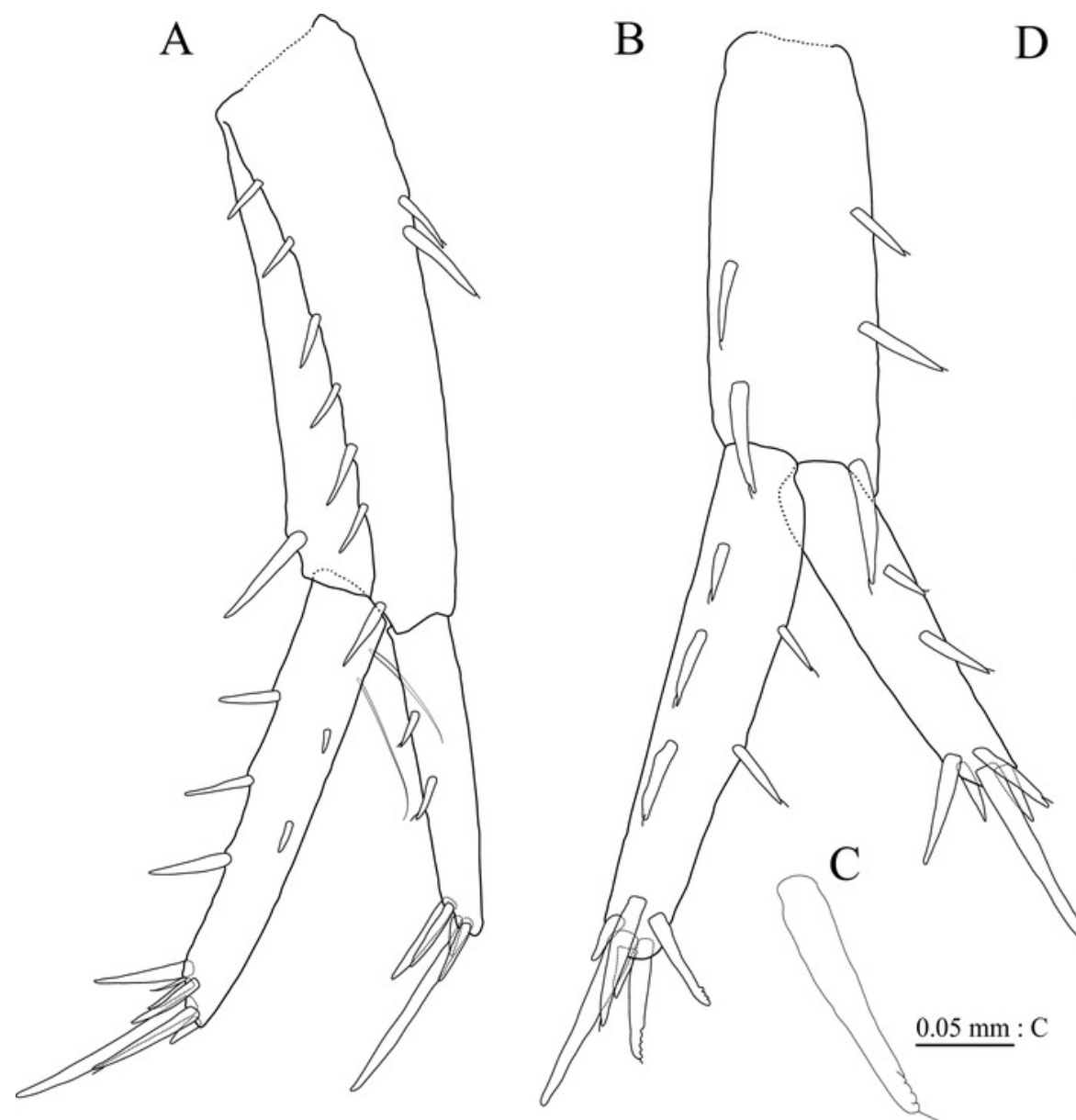

$1.0 \mathrm{~mm}: \mathrm{A}, \mathrm{D}$

$1.0 \mathrm{~mm}: \mathrm{B}$

$1.0 \mathrm{~mm}: \mathrm{F}$
$\mathrm{D}$

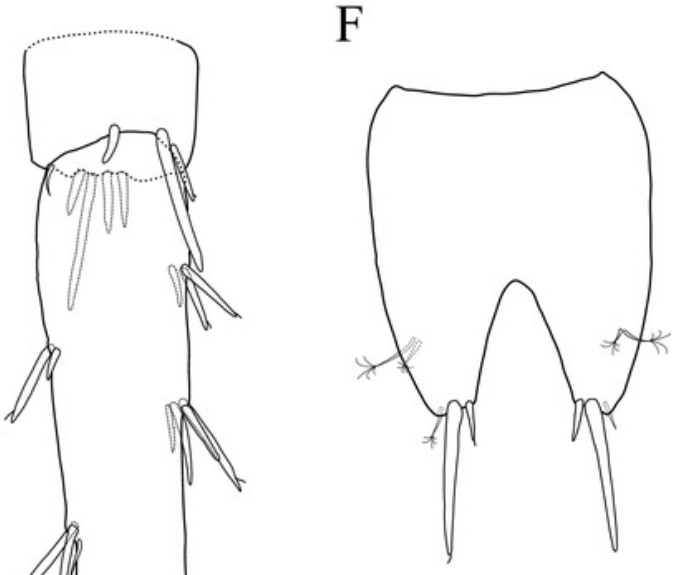

$\mathrm{E}$

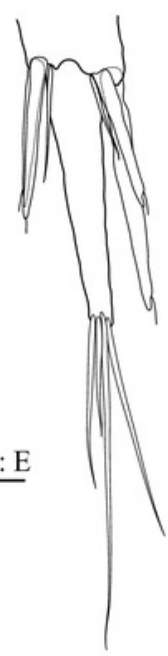




\section{Figure 9}

Holotype of Pseudocrangonyx kwangcheonseonensis sp. nov. (NNIBRIV35120).

(A) Antenna 1, medial view; (B) Accessory flagellum of antenna 1, medial view; (C) Antenna 2, lateral view; (D) Calceolus of antenna 2, lateral view; (E) Upper lip, posterior view; (F) Right mandible, medial view; (G) Incisor, lacinia mobilis, and molar process of right mandible, medial view; (H) Incisor, lacinia mobilis, and molar process of left mandible, medial view; (I) Lower lip, dorsal view; (J) Maxilla 1, dorsal view; (K) Apical robust setae on outer plate of maxilla 1, dorsal view; (L) Maxilla 2, dorsal view. 


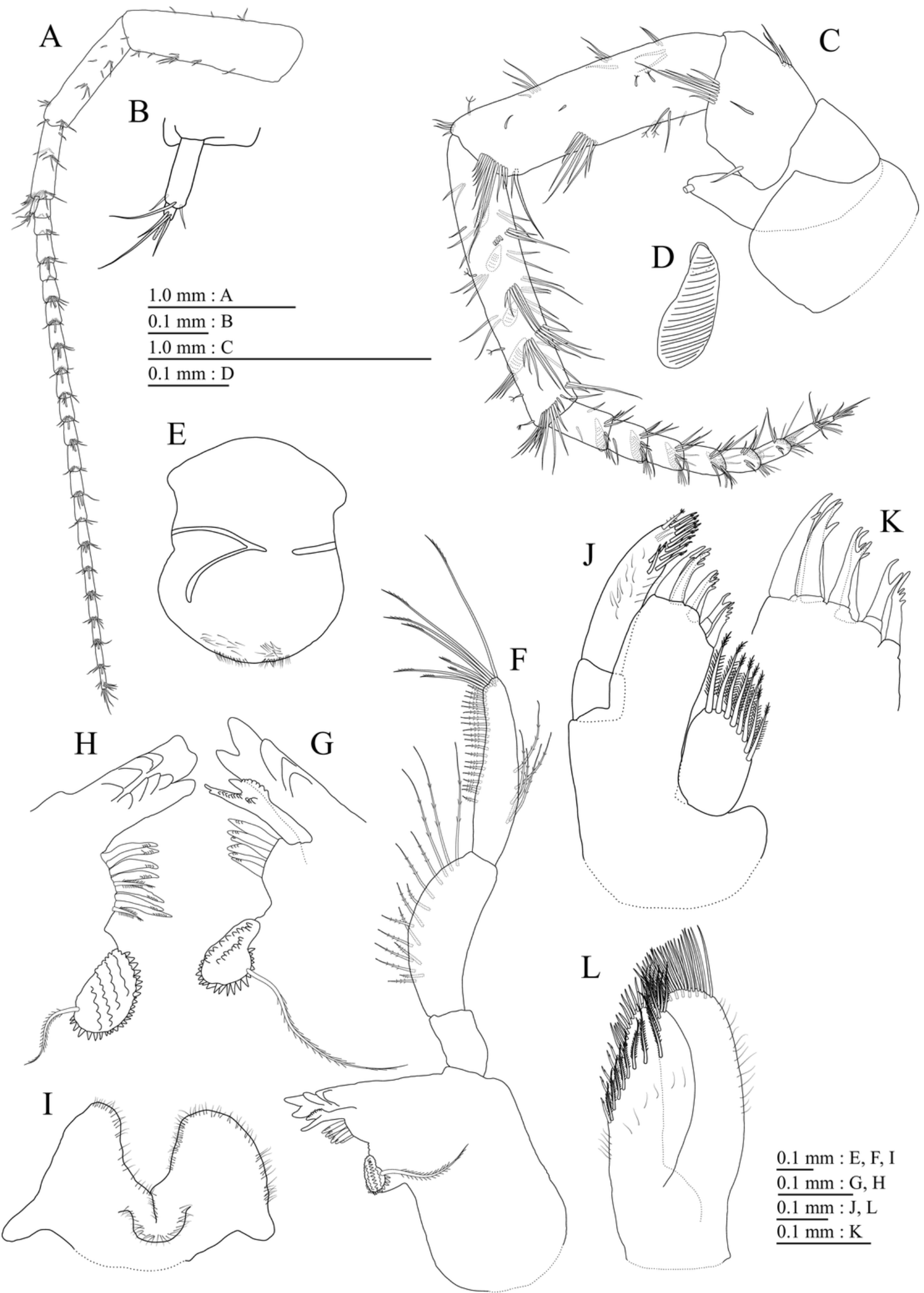


Figure 10

Holotype of Pseudocrangonyx kwangcheonseonensis sp. nov. (NNIBRIV35120).

(A) Maxilliped, dorsal view; (B) Gnathopod 1, medial view; (C) Serrate setae on posterodistal corner of carpus of gnathopod 1, lateral view; (D) Palmar margin of propodus and dactylus of gnathopod 1, medial view; (E) Gnathopod 2, medial view; (F) Serrate setae on posterodistal corner of carpus of gnathopod 2, lateral view; (G) Palmar margin of propodus and dactylus of gnathopod 2, medial view.
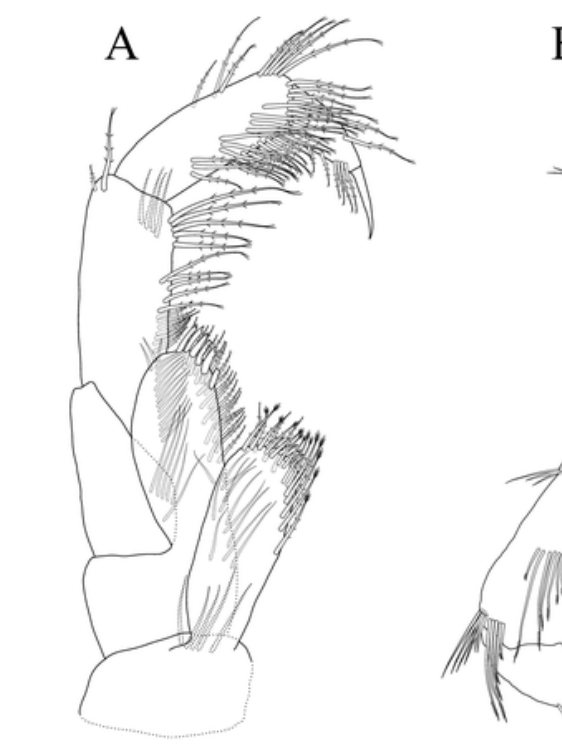

B
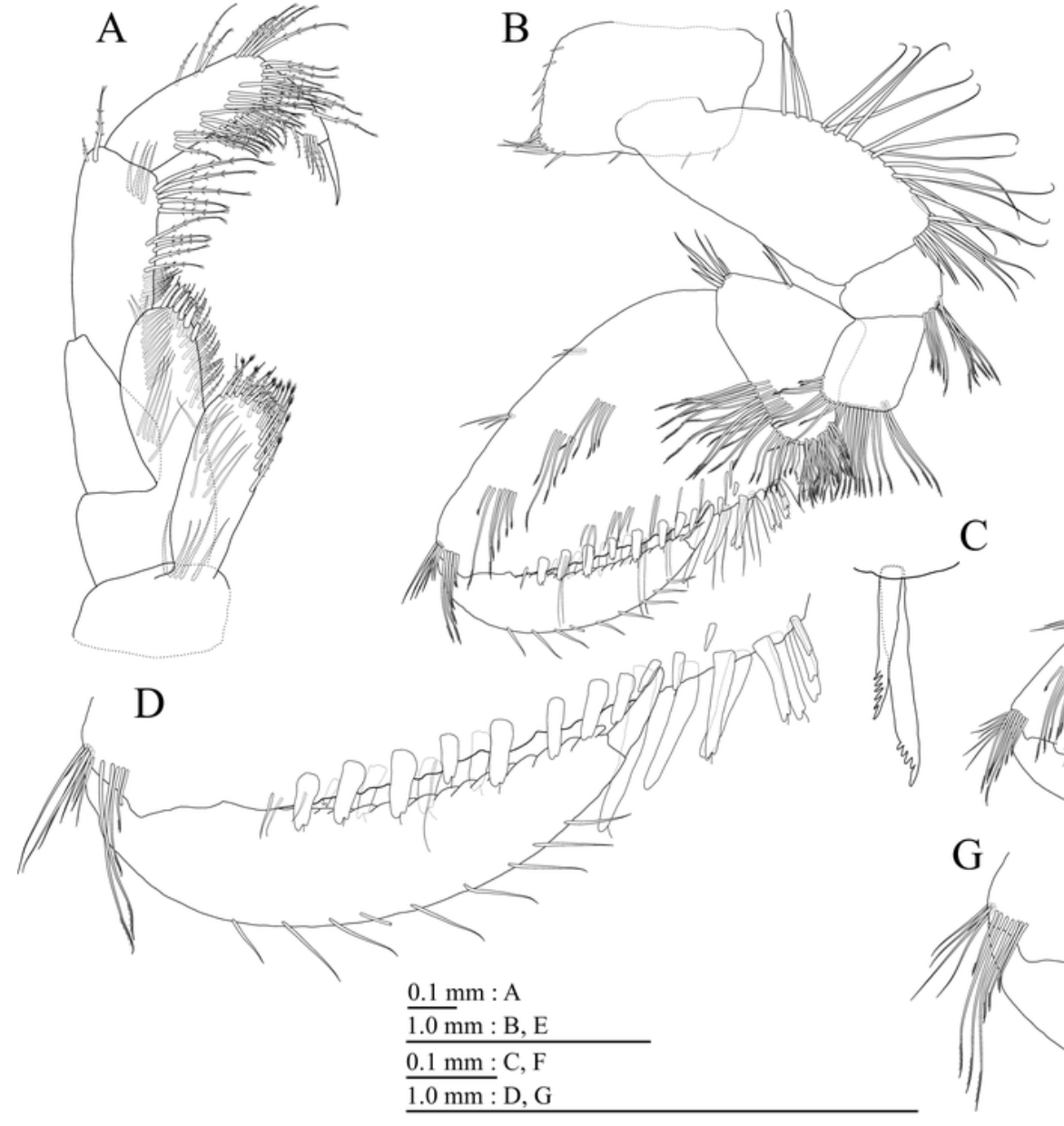

E
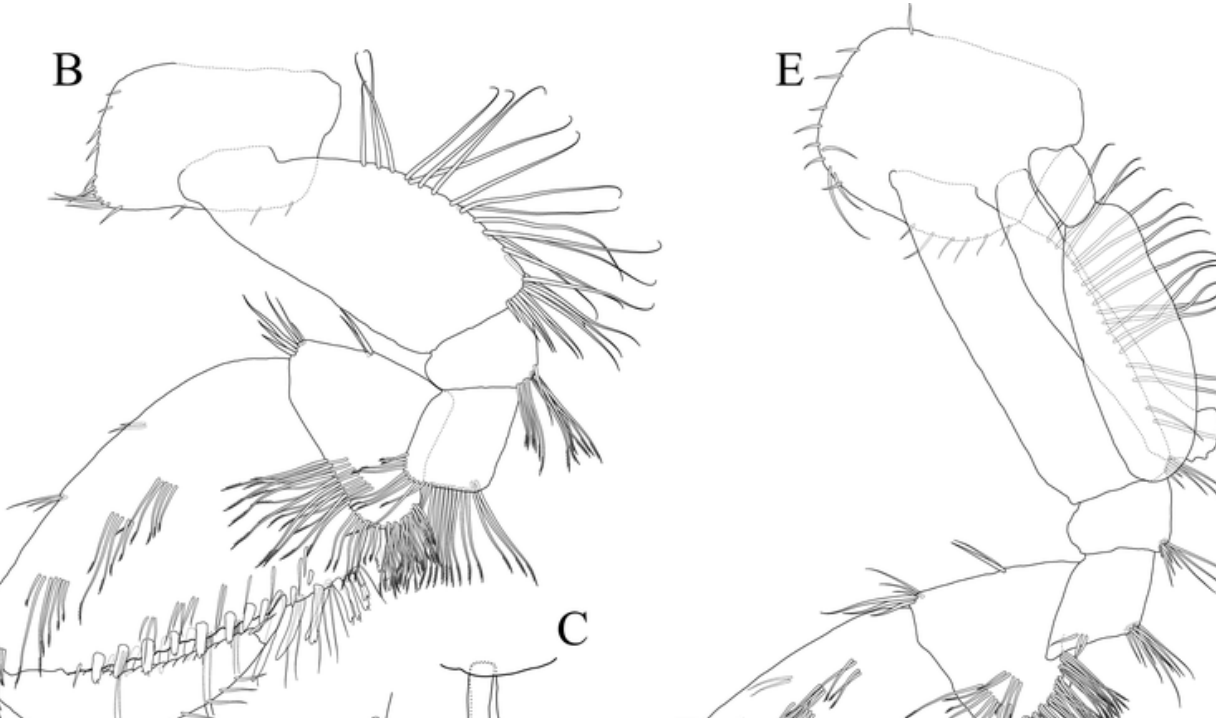
Figure 11

Holotype of Pseudocrangonyx kwangcheonseonensis sp. nov. (NNIBRIV35120).

(A) Pereopod 3, medial view; (B) Dactylus of pereopod 3, medial view; (C) Pereopod 4, medial view; (D) Dactylus of pereopod 4, medial view; (E) Pereopod 5, medial view; (F) Dactylus of pereopod 5, medial view; (G) Pereopod 6, medial view; (H) Pereopod 7, medial view; (I) Dactylus of pereopod 7, medial view.

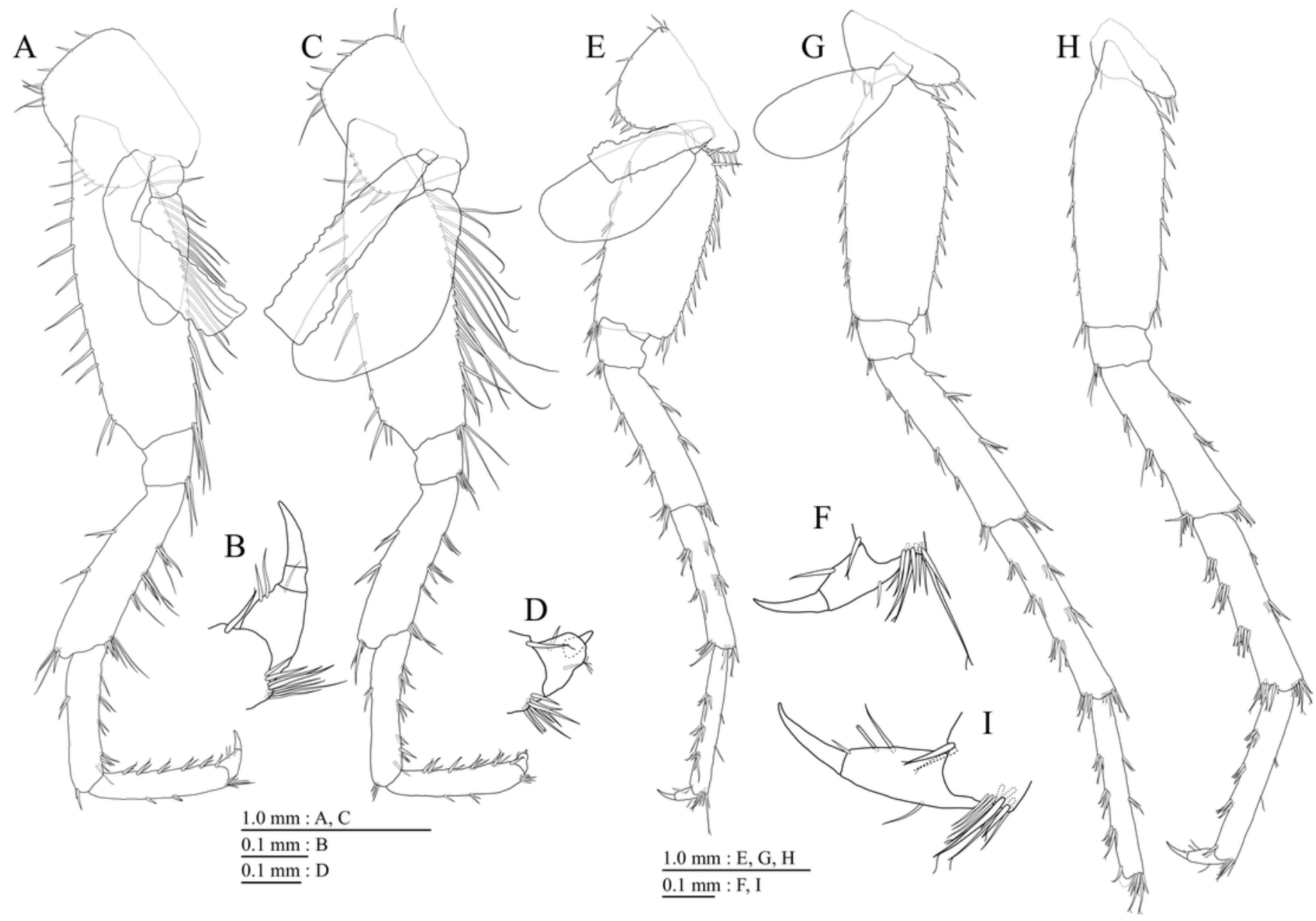




\section{Figure 12}

Holotype of Pseudocrangonyx kwangcheonseonensis sp. nov. (NNIBRIV35120).

(A) Sternal gills on pereonites 2-4, lateral view; (B) Pleopod 1, lateral view; (C) Retinacula on peduncle of pleopod 1, lateral view; (D) Pleopod 2, lateral view; (E) Retinacula on peduncle of pleopod 2, lateral view; (F) Pleopod 3, lateral view; (G) Retinacula on peduncle of pleopod 3, lateral view; (H) Uropod 1, dorsal view; (I) Uropod 2, dorsal view; (J) Uropod 3, dorsal view; (K) Terminal article of uropod 3, dorsal view; (L) Telson, ventral view. 


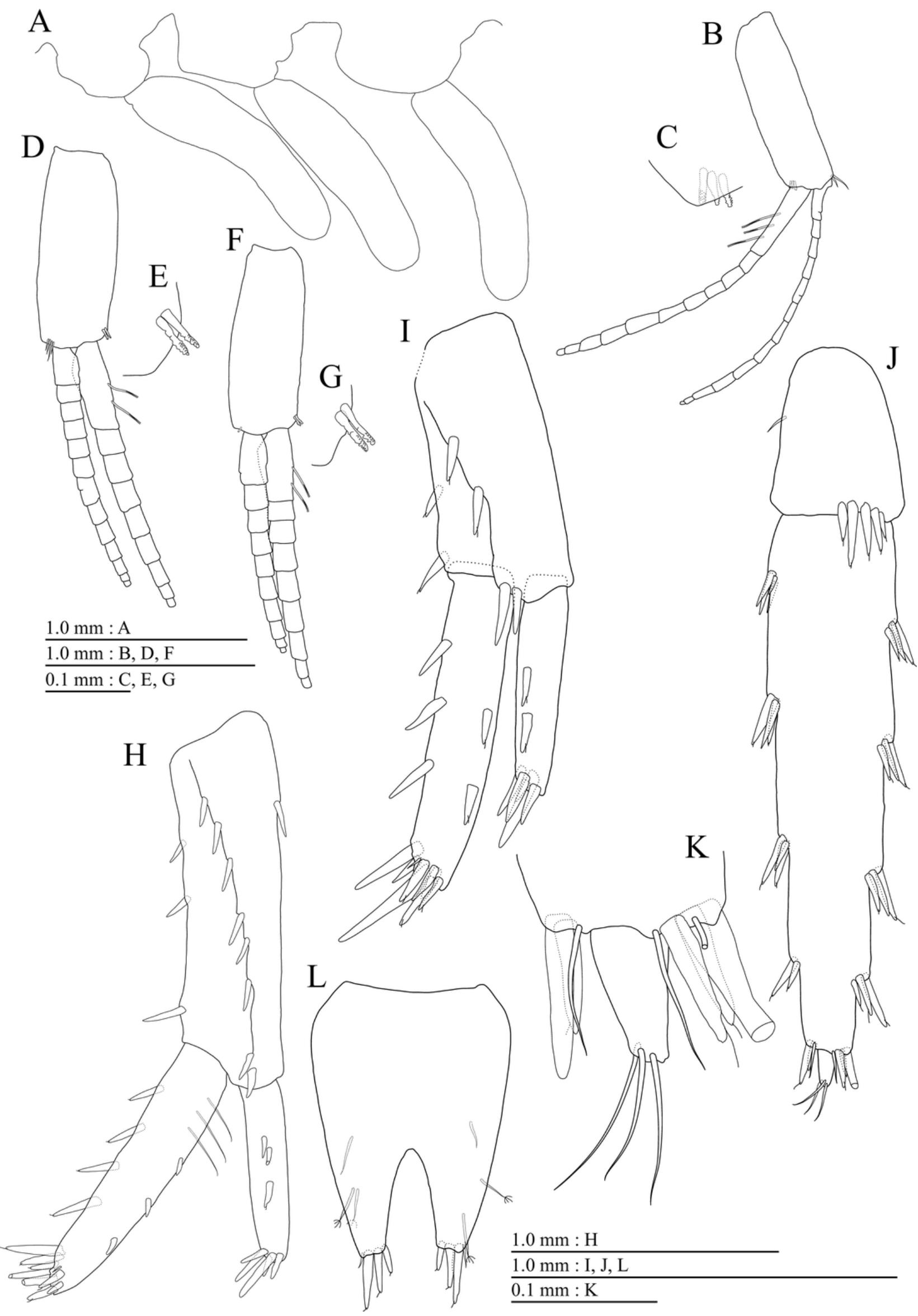




\section{Figure 13}

Paratype of Pseudocrangonyx kwangcheonseonensis sp. nov. (NNIBRIV39840).

(A) Antenna 1, lateral view; (B) Accessory flagellum of antenna 1, lateral view; (C) Antenna 2, medial view; (D) Gnathopod 1, medial view; (E) Serrate setae on posterodistal corner of carpus of gnathopod 1, lateral view; (F) Palmar margin of propodus and dactylus of gnathopod 1, medial view; (G) Gnathopod 2, medial view; (H) Serrate setae on posterodistal corner of carpus of gnathopod 2, lateral view; (I) Palmar margin of propodus and dactylus of gnathopod 2, medial view.

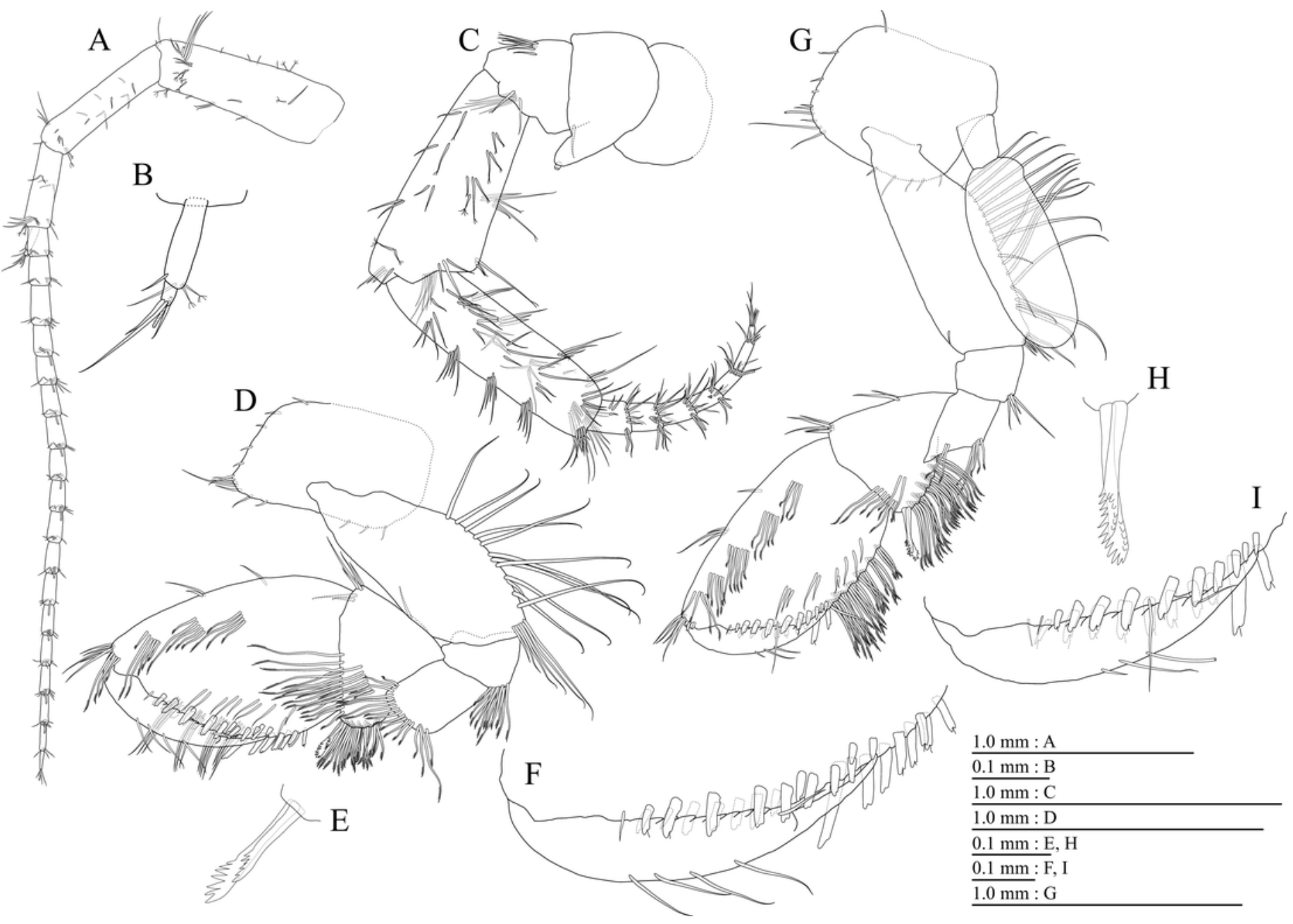


Figure 14

Paratype of Pseudocrangonyx kwangcheonseonensis sp. nov. (NNIBRIV39840).

(A) Uropod 1, dorsal view; (B) Uropod 2, dorsal view; (C) Uropod 3, dorsal view; (D) Terminal article of uropod 3, dorsal view; (E) Telson, dorsal view.
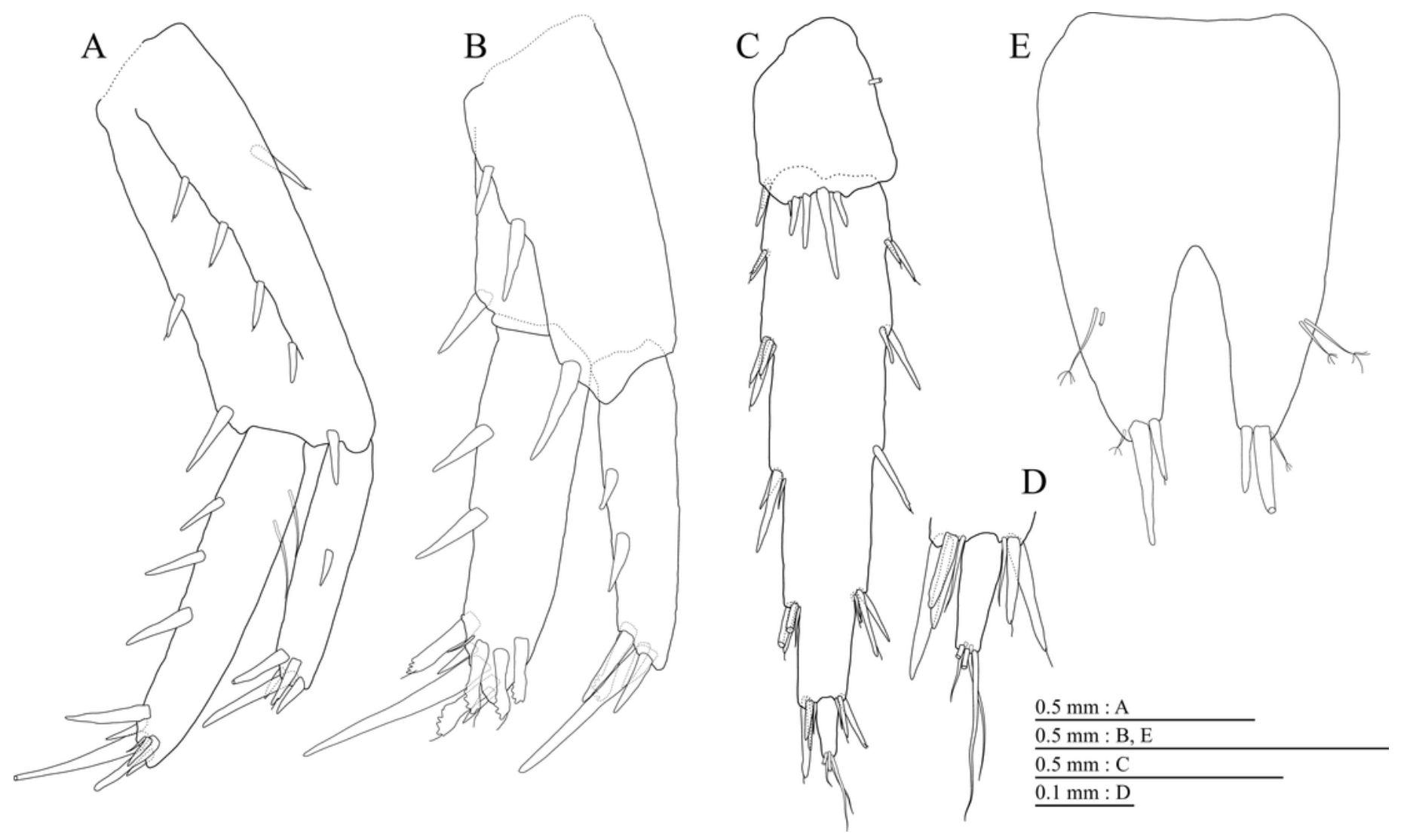


\section{Figure 15}

Holotype of Pseudocrangonyx hwanseonensis sp. nov. (NNIBRIV35118).

(A) Antenna 1, medial view; (B) Accessory flagellum of antenna 1, medial view; (C) Antenna 2, medial view; (D) Calceolus of antenna 2, medial view; (E) Upper lip, posterior view; (F) Left mandible, medial view; (G) Incisor, lacinia mobilis, and molar process of right mandible, medial view; (H) Lower lip, ventral view; (I) Maxilla 1, dorsal view; (J) Maxilla 2, dorsal view. 


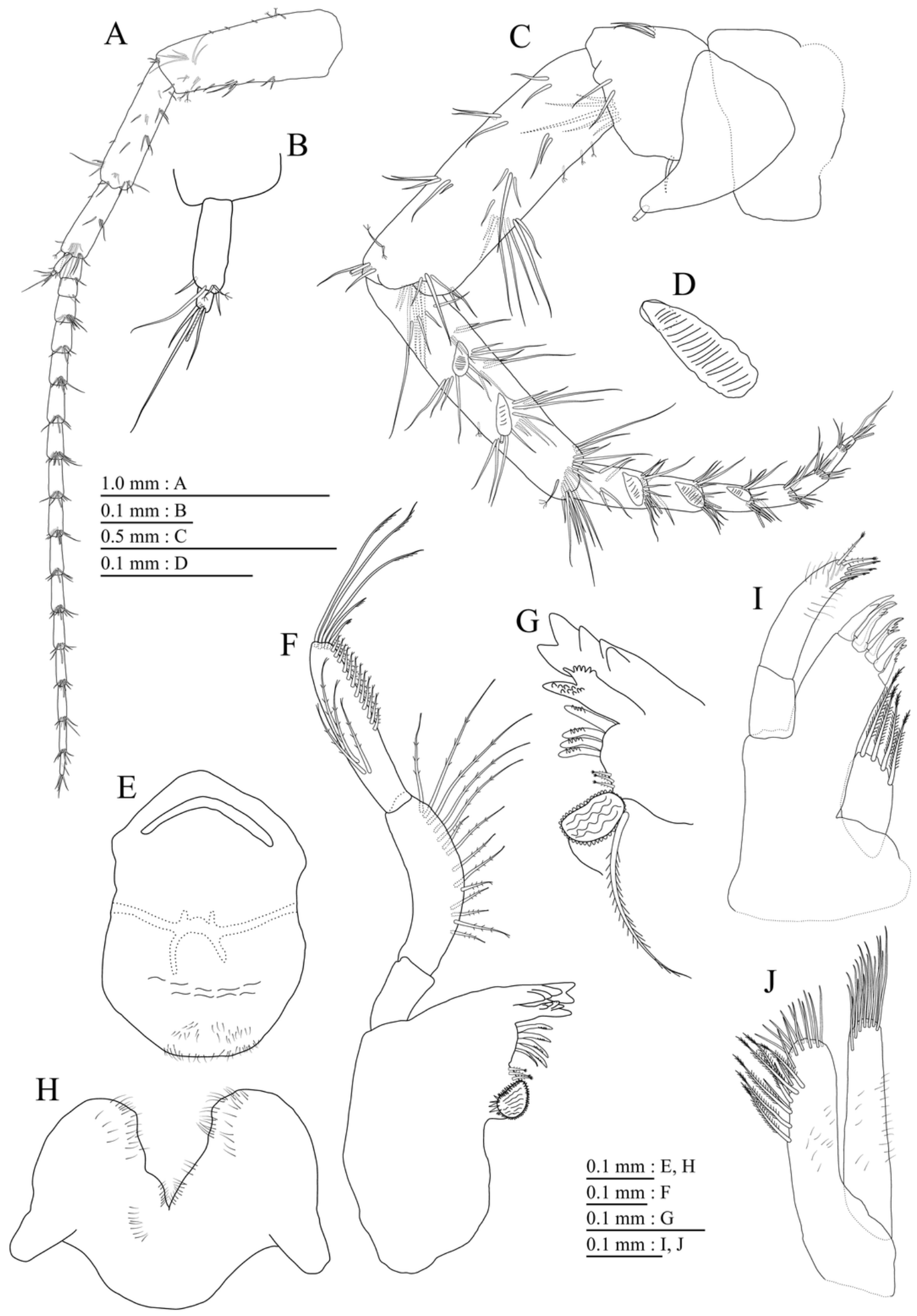


Figure 16

Holotype of Pseudocrangonyx hwanseonensis sp. nov. (NNIBRIV35118).

(A) Maxilliped, dorsal view; (B) Gnathopod 1, lateral view; (C) Serrate setae on posterodistal corner of carpus of gnathopod 1, lateral view; (D) Palmar margin of propodus and dactylus of gnathopod 1, lateral view; (E) Gnathopod 2, lateral view; (F) Serrate setae on posterodistal corner of carpus of gnathopod 2, lateral view; (G) Palmar margin of propodus and dactylus of gnathopod 2, lateral view.

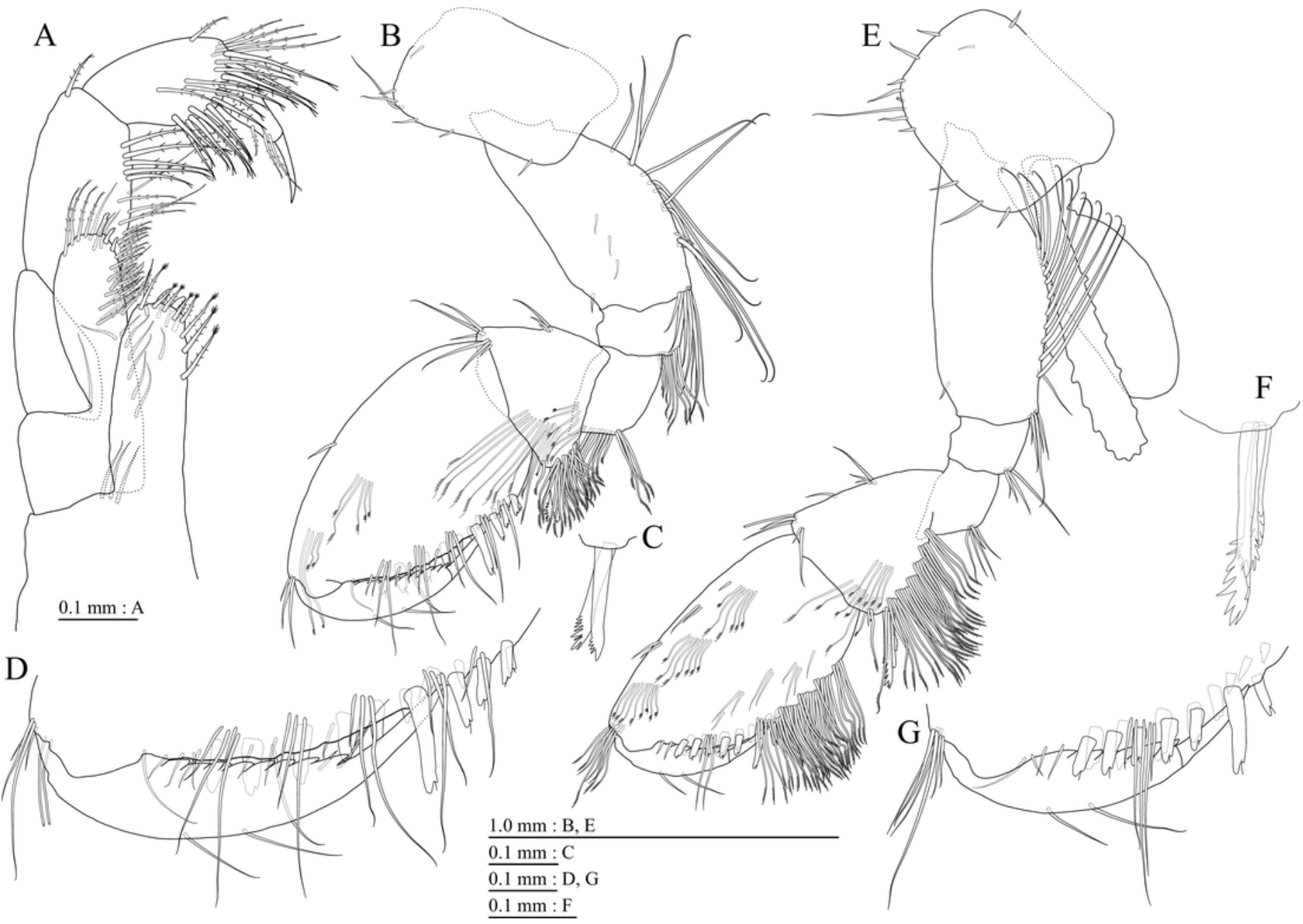




\section{Figure 17}

Holotype of Pseudocrangonyx hwanseonensis sp. nov. (NNIBRIV35118).

(A) Pereopod 3, lateral view; (B) Dactylus of pereopod 3, lateral view; (C) Pereopod 4, lateral view; (D) Dactylus of pereopod 4, lateral view; (E) Pereopod 5, lateral view; (F) Dactylus of pereopod 5, lateral view; (G) Pereopod 6, lateral view; (H) Dactylus of pereopod 6, lateral view; (I) Pereopod 7, lateral view; (J) Dactylus of pereopod 7, lateral view.

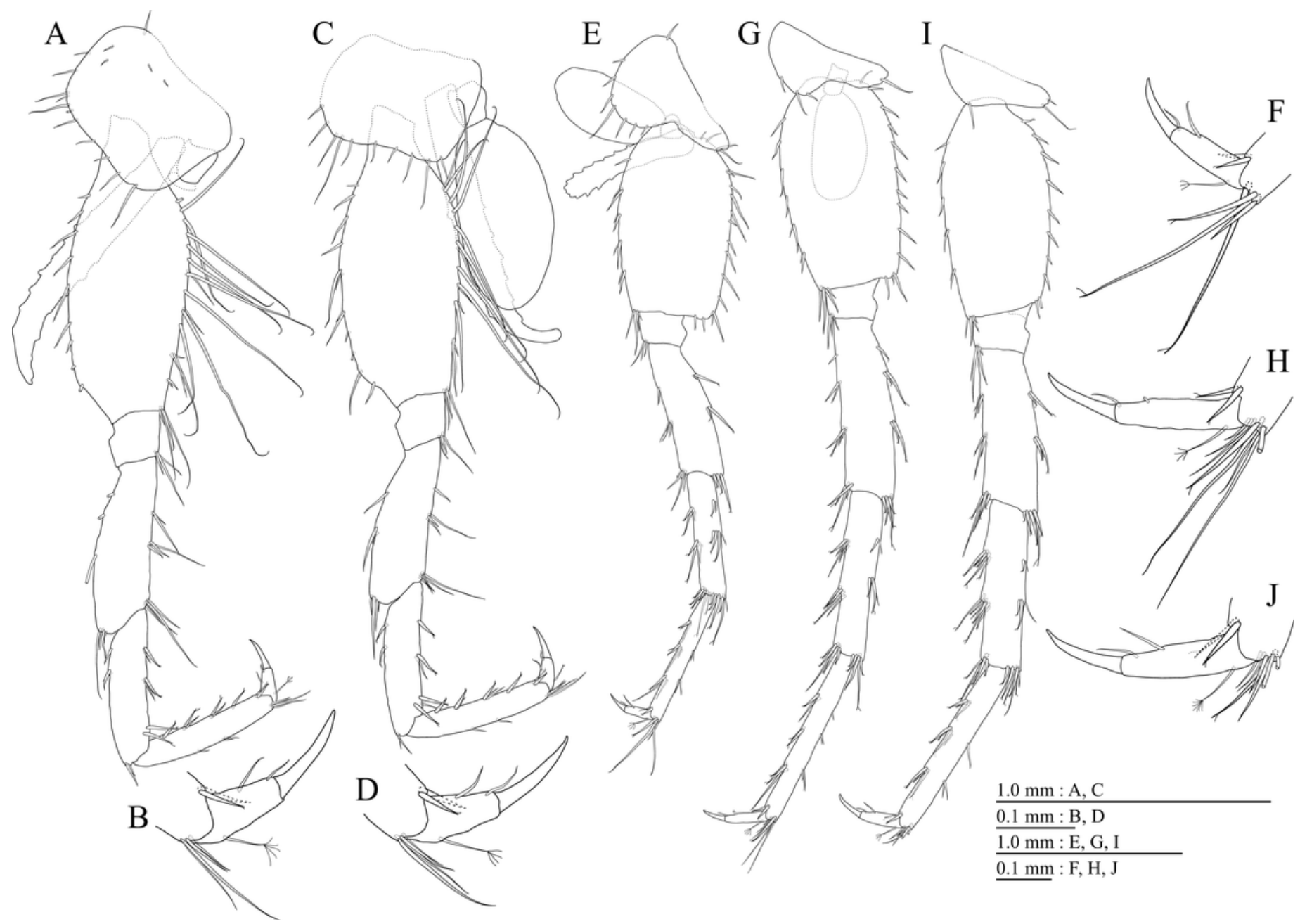




\section{Figure 18}

Holotype of Pseudocrangonyx hwanseonensis sp. nov. (NNIBRIV35118).

(A) Sternal gills on pereonites 2-4, lateral view; (B) Pleopod 1, lateral view; (C) Retinacula on peduncle of pleopod 1, lateral view; (D) Pleopod 2, lateral view; (E) Retinacula on peduncle of pleopod 2, lateral view; (F) Pleopod 3, lateral view; (G) Retinacula on peduncle of pleopod 3, lateral view; (H) Uropod 1, dorsal view; (I) Uropod 2, ventral view; (J) Uropod 3, dorsal view; (K) Terminal article of uropod 3, dorsal view; (L) Telson, dorsal view. 
A

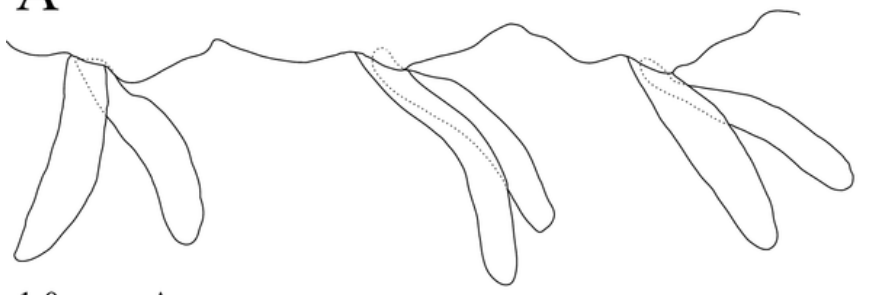

$1.0 \mathrm{~mm}: \mathrm{A}$
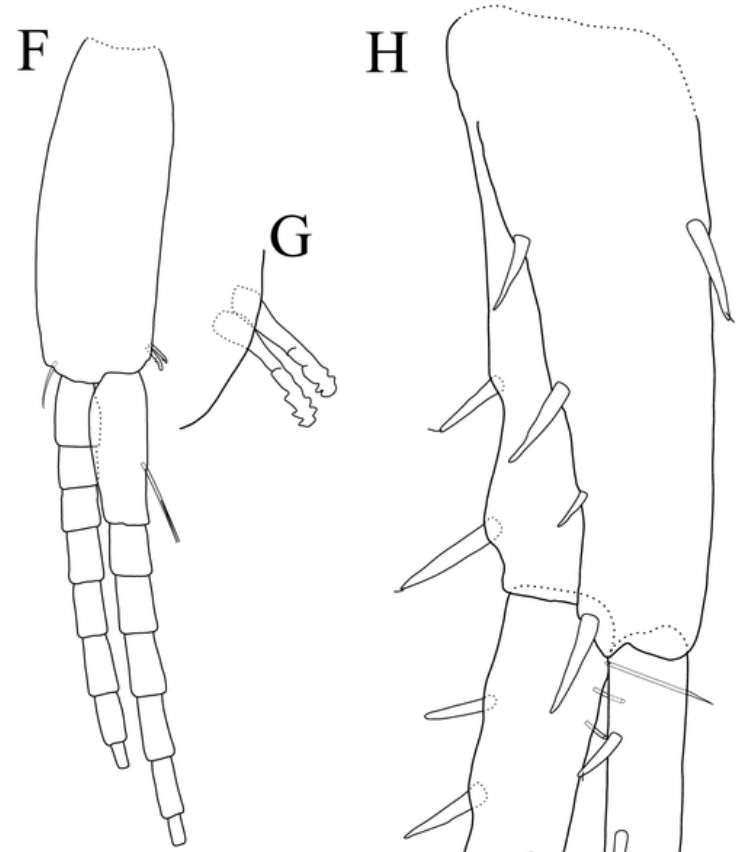

$\mathrm{L}$
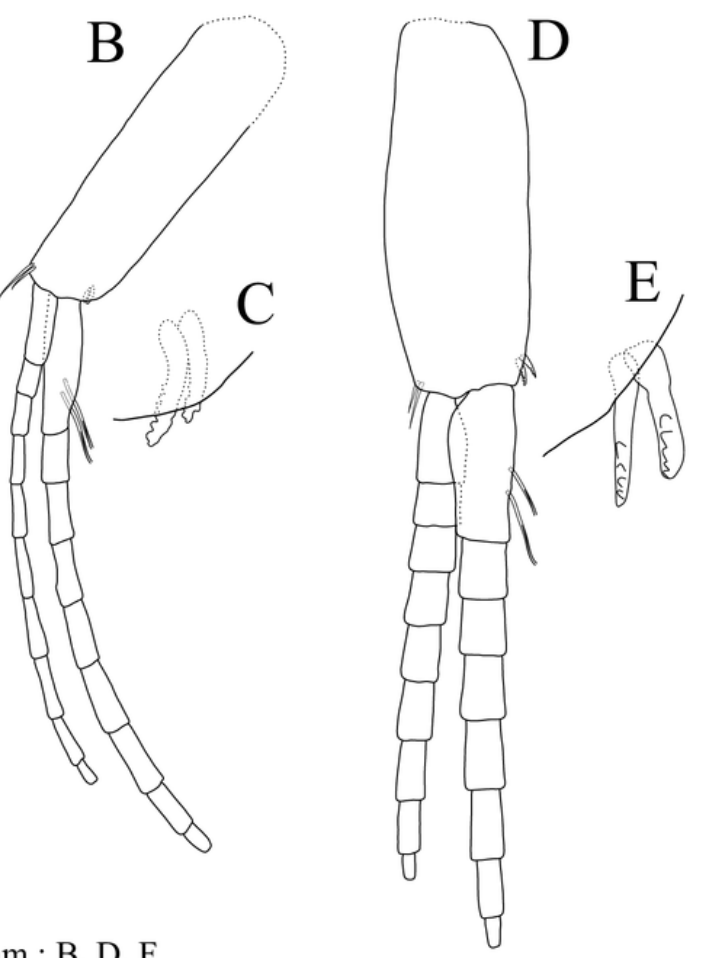

$1.0 \mathrm{~mm}: \mathrm{B}, \mathrm{D}, \mathrm{F}$ $0.1 \mathrm{~mm}: \mathrm{C}, \mathrm{E}, \mathrm{G}$

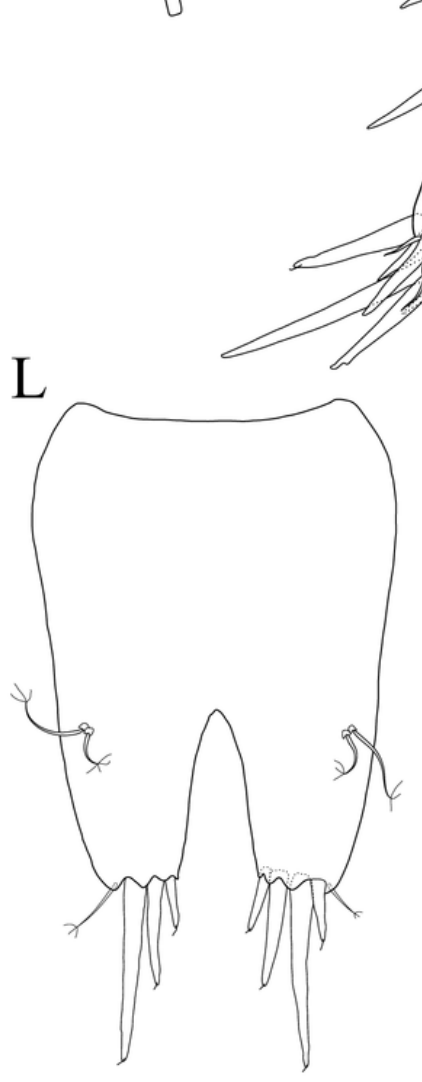




\section{Figure 19}

Paratype of Pseudocrangonyx hwanseonensis sp. nov. (NNIBRIV39837).

(A) Antenna 1, medial view; (B) Accessory flagellum of antenna 1, medial view; (C) Antenna 2, medial view; (D) Calceolus of antenna 2, medial view; (E) Gnathopod 1, lateral view; (F) Serrate setae on posterodistal corner of carpus of gnathopod 1, lateral view; (G) Palmar margin of propodus and dactylus of gnathopod 1, lateral view; $(H)$ Gnathopod 2, lateral view; (I) Serrate setae on posterodistal corner of carpus of gnathopod 2, lateral view; (J) Palmar margin of propodus and dactylus of gnathopod 2, lateral view. 


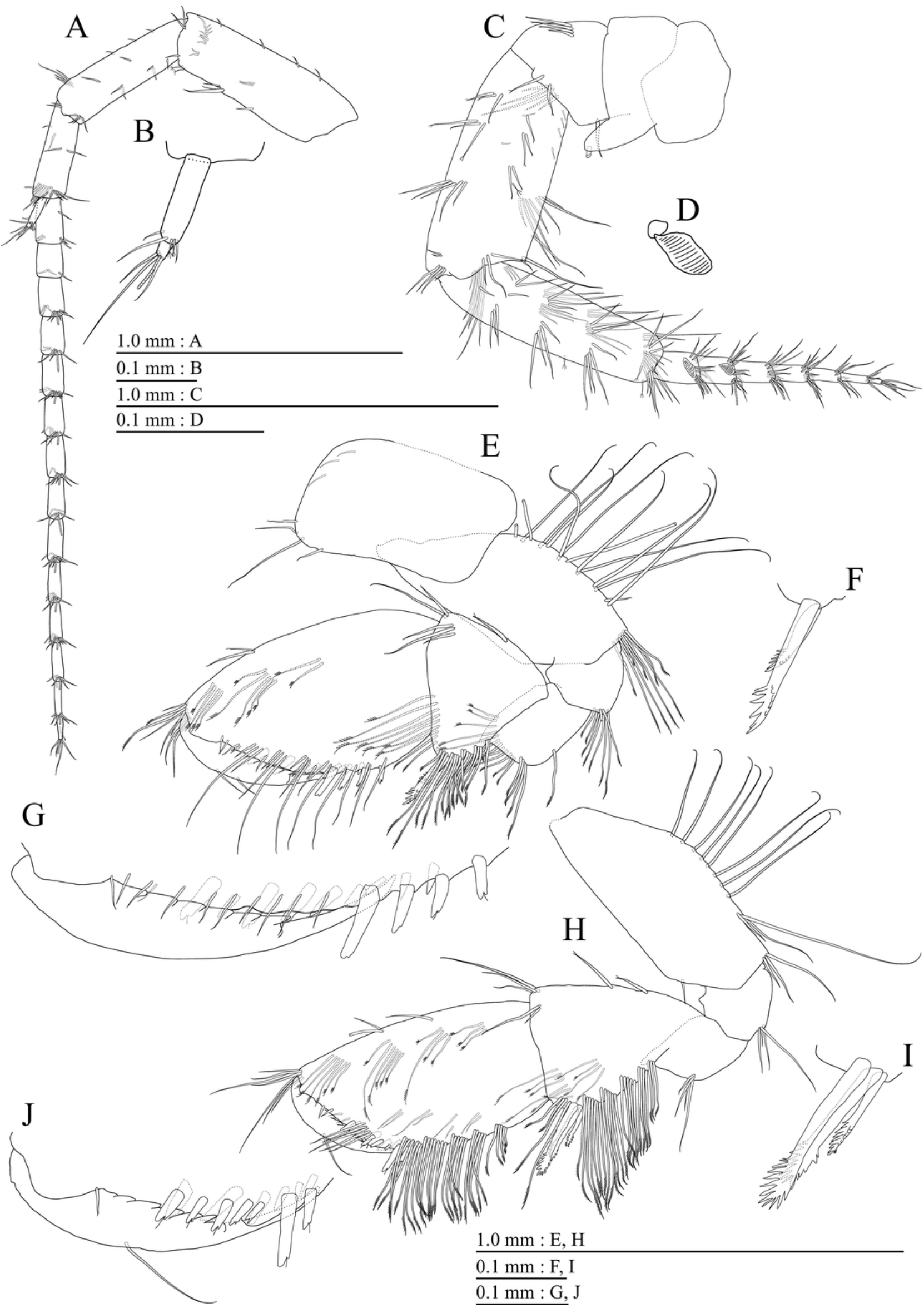

Peer) reviewing PDF | (2020:10:54037:1:0:NEW 22 Dec 2020) 
Figure 20

Paratype of Pseudocrangonyx hwanseonensis sp. nov. (NNIBRIV39837).

(A) Uropod 1, dorsal view; (B) Uropod 2, dorsal view; (C) Uropod 3, dorsal view; (D) Terminal article of uropod 3, dorsal view; (E) Telson, dorsal view.
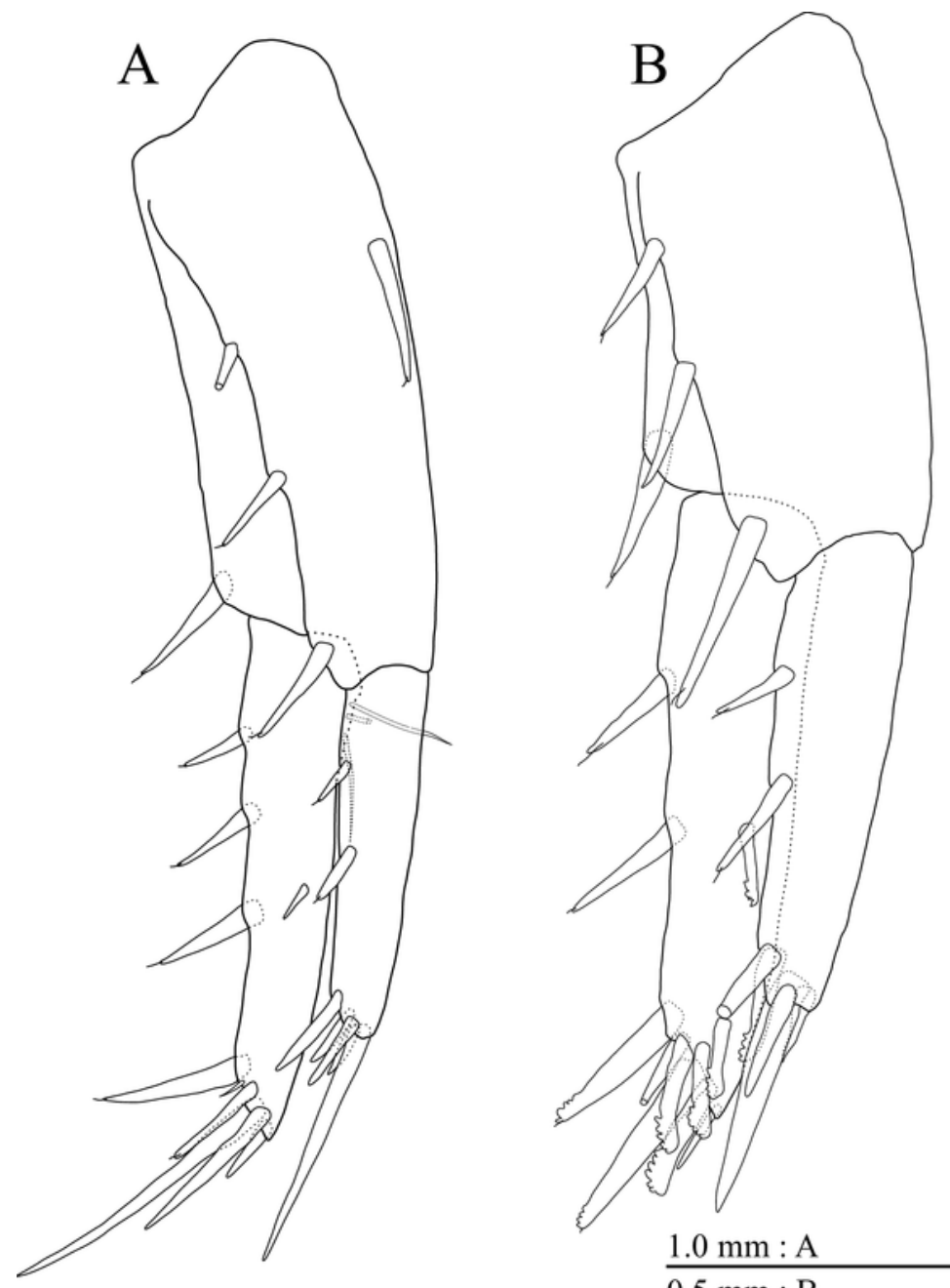

$$
\begin{aligned}
& \frac{1.0 \mathrm{~mm}: \mathrm{A}}{0.5 \mathrm{~mm}: \mathrm{B}} \\
& 0.5 \mathrm{~mm}: \mathrm{C}, \mathrm{E} \\
& \hline 0.1 \mathrm{~mm}: \mathrm{D} \\
& \hline
\end{aligned}
$$

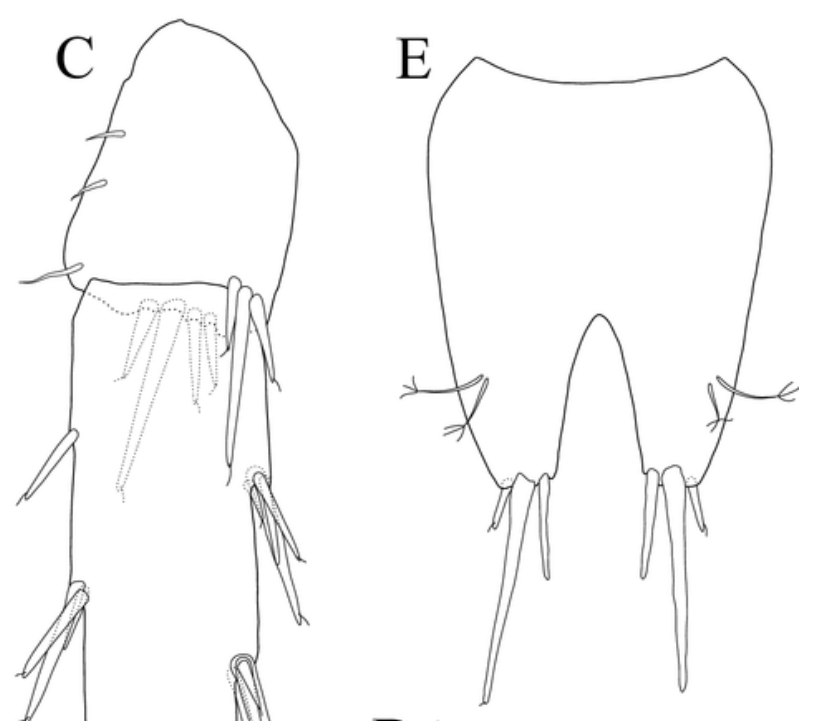

$\mathrm{D}$

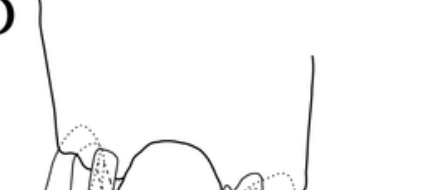


Figure 21

Maximum likelihood and Bayesian inference analyses based on nuclear 28S rRNA and mitochondrial COI sequences. Numbers on nodes represent bootstrap values for maximum likelihood and Bayesian posterior probabilities.

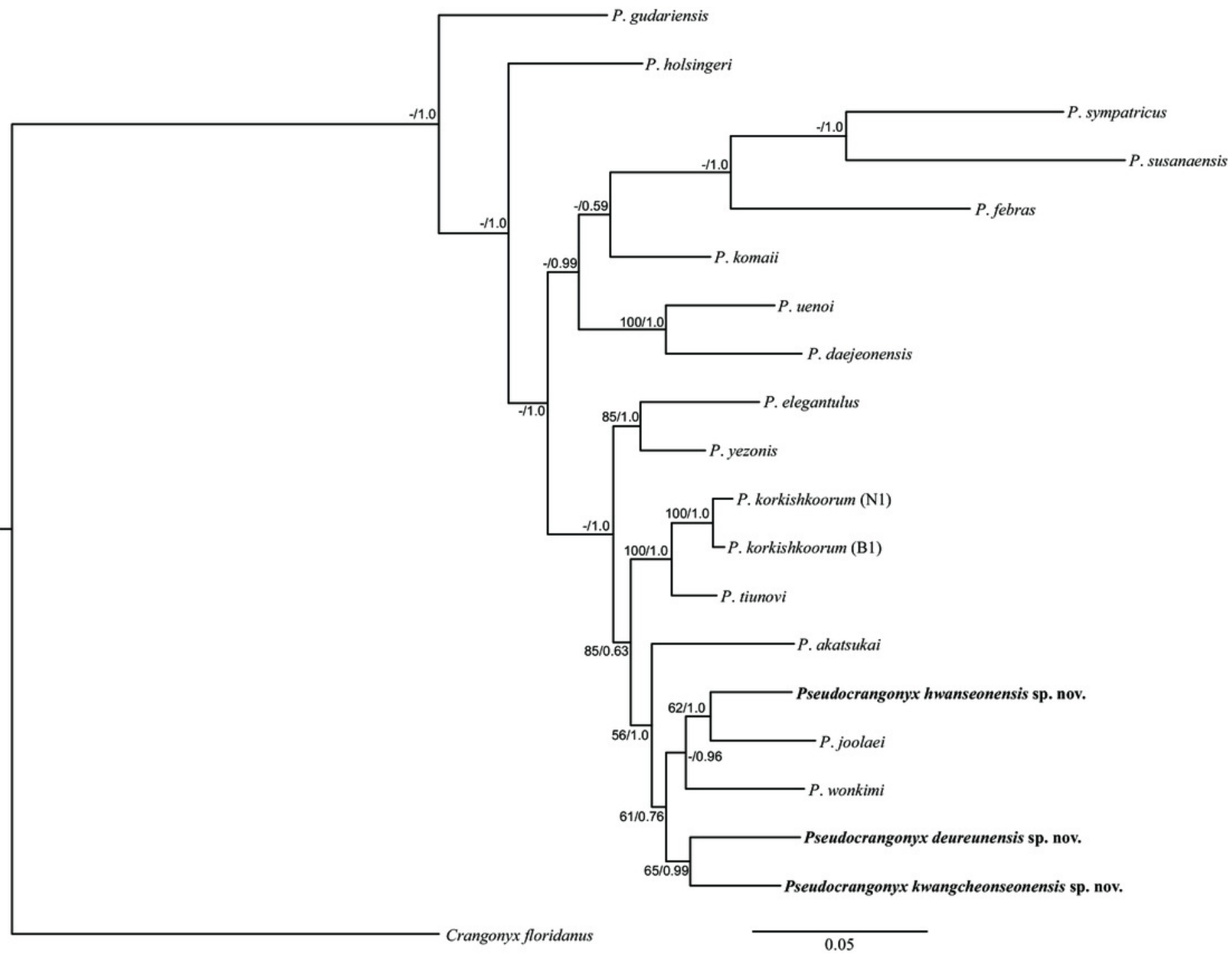

